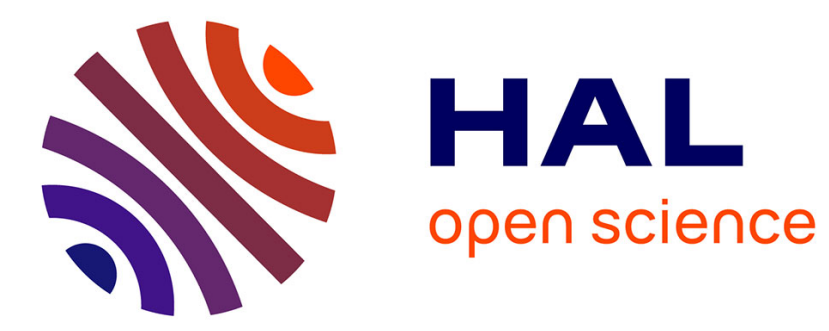

\title{
Formal education and public knowledge
}

Maurizio Iacopetta

\section{To cite this version:}

Maurizio Iacopetta. Formal education and public knowledge. Journal of Economic Dynamics and

Control, 2011, 35 (5), pp.676. 10.1016/j.jedc.2011.01.006 . hal-00796303

\section{HAL Id: hal-00796303 \\ https://hal.science/hal-00796303}

Submitted on 3 Mar 2013

HAL is a multi-disciplinary open access archive for the deposit and dissemination of scientific research documents, whether they are published or not. The documents may come from teaching and research institutions in France or abroad, or from public or private research centers.
L'archive ouverte pluridisciplinaire HAL, est destinée au dépôt et à la diffusion de documents scientifiques de niveau recherche, publiés ou non, émanant des établissements d'enseignement et de recherche français ou étrangers, des laboratoires publics ou privés. 


\section{Author's Accepted Manuscript}

Formal education and public knowledge

Maurizio Iacopetta

PII: $\quad$ S0165-1889(11)00007-8

DOI: $\quad$ doi:10.1016/j.jedc.2011.01.006

Reference: DYNCON 2527

To appear in: $\quad$ Journal of Economic Dynamics \& Control

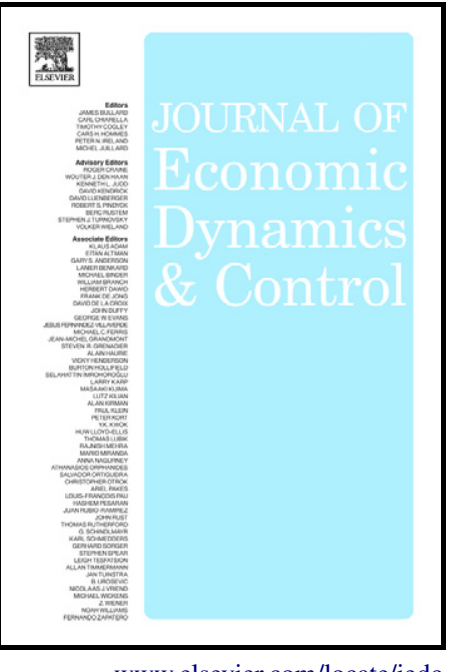

www.elsevier.com/locate/jedc

Received date: 8 April 2009

Revised date: 3 September 2010

Accepted date: 8 December 2010

Cite this article as: Maurizio Iacopetta, Formal education and public knowledge, Journal of Economic Dynamics \& Control, doi:10.1016/j.jedc.2011.01.006

This is a PDF file of an unedited manuscript that has been accepted for publication. As a service to our customers we are providing this early version of the manuscript. The manuscript will undergo copyediting, typesetting, and review of the resulting galley proof before it is published in its final citable form. Please note that during the production process errors may be discovered which could affect the content, and all legal disclaimers that apply to the journal pertain. 


\title{
Formal Education and Public Knowledge
}

\author{
Maurizio Iacopetta \\ OFCE Sciences-Po and Skema Business School*
}

\begin{abstract}
In this paper, I examine the transitional dynamics of an economy populated by individuals who split their time between acquiring a formal education, producing final goods, and innovating.

The paper has two objectives: (i) uncovering the macroeconomic circumstances that favored the rise of formal education; (ii) to reconcile the remarkable growth of the education sector with the constancy of other key macroeconomic variables, such as the interest rate, the consumption-output ratio, and the growth rate of per capita income (Kaldor facts).

The transitional dynamics of human capital growth models, such as Lucas (1988), would attribute the arrival of education to the diminishing marginal productivity of physical capital. Conversely, the model proposed here suggests that it is the rate of learning that catches up with the rate of return on physical capital. As technical knowledge expands, the rate of return on education increases, inducing individuals to stay longer in school. The model's transitional paths are matched with long run U.S. educational and economic data.

Keywords: Public Knowledge, Learning Rate, Transitional Dynamics, Calibration. JEL codes: J24, N30, O33.
\end{abstract}

\section{Introduction}

The average years of schooling of the labor force in the U.S. grew in the period 1840-2000 from 1.14 to 13. A similar remarkable expansion of education is observed in all contemporary high income countries and in most developing countries (Baier et al., 2007; Schofer and Meyer, 2005).

${ }^{*}$ Correspondence to: maurizio.iacopetta@sciences-po.org. Three appendices to this work are posted at http://hp.gredeg.cnrs.fr/maurizio_iacopetta. 
This paper interprets the rise of formal education as a transitional phenomenon of an endogenous growth model in which both innovation and education are the engines of growth. The transitional dynamics of Lucas (1988) imply that the greater allocation of time to education is the consequence of a decline in the marginal productivity of physical capital. When investments in physical capital yield a return higher than investment in human capital, there is no incentive for individuals to go to school. As physical capital expands, its rate of return declines, and resources are diverted into human capital accumulation. Nevertheless, the data do not show any significant long-term decline in capital returns. The calculation of Barro (2006) and Siegel (1998) suggests that the average real bill and stock returns in the 19 th century are about the same as those recorded in the 20 th century. ${ }^{1}$

The alternative hypothesis explored in this paper is that the productivity of the time spent in school has historically caught up with capital productivity, leading to a greater allocation of time in education. I will argue that the expansion of public knowledge was the main force behind the improvement in productivity in the education sector.

The conjecture rests on three observations. First, public knowledge is a major input of the education sector. By public knowledge I mean the content of information goods, such as books, electronic files, drawings, and artifacts, that can be studied for the sake of solving production problems more efficiently or for generating new ideas. Casual observation suggests that information goods are invariably used in schools. Second, technological advances unfold new public knowledge. When a new kind of bridge is built, the frontier of technical knowledge is pushed forward. Individuals can replicate the original bridge by studying its blueprint, or by learning directly the technique from the constructors of the original bridge. Likewise, when a firm adopts a new principle of organization, interested individuals have more information about the ways production can be carried out. ${ }^{2}$ Third, the unfolding of new technological knowledge induces to modifications of educational curricula. When an innovation is deemed to be important enough, existing textbooks on the subject are updated, new textbooks are written, and sometimes entire new schools are established. Indeed, a great deal of educational innovation occurred in the past century, and, arguably, most of it is associated with technological progress. For instance, advances in the industries of electricity,

\footnotetext{
${ }^{1}$ Table IV of Barro (2006) shows that the real stock return in the United States for the 1880-2004 and 1954-2004 time periods are 0.081 and 0.089, respectively. The real bill return for the same two periods is 0.015 and 0.017 , respectively. Siegel (1998) calculates a return of $7 \%$ for the periods $1802-1997,1871-1997$ and of $6.7 \%$ for the period 1913-1997 (see Table 8-1).

${ }^{2}$ Dosi and Nelson (2010) give an excellent overview of the competing interpretations of technological knowledge. They focus on artifacts, routines, and recipes. Recipes, being codified knowledge, have the character of a public good. A routine can, to a certain extent, be also codified, but often tacit knowledge (i.e. rival human capital) is needed for practical applications. Not always can public knowledge be generated from an artifact. Nevertheless, there are historical examples of this kind of knowledge generation: Renaissance architects learned a great deal by observing building designs from the Classical period.
} 
broadcasting and communication, as well as the spread of radars, guided missiles and control systems, prompted a number of reforms in electrical engineering curricula (Terman,1998 $[1976]) .^{3}$

The interaction between technological progress, education, and public knowledge will be analyzed within a growth model in which the representative individual decides how to optimally allocate time between production, schooling, and innovation activities. One novelty of the model is the incorporation of a mechanism whereby innovation activities generate positive externalities that benefit the education sector: Current students can tap into a larger set of public knowledge than the one available to previous generations of students. ${ }^{4}$ The focus of the analysis is on the transitional dynamics of the model economy. As technology advances, new knowledge unfolds and, as a result, the learning rate goes up. During the transition, the interest rate plays a negligible role in driving the economy towards the balanced growth path for two reasons: (i) The accumulation of public knowledge, by improving the productivity of the final good sector, prevents the otherwise inevitable interest rate decline; (ii) there is no need for an interest drop to induce individuals to invest in schooling, because public knowledge gradually lifts up the education function.

This paper is related to the literature that emphasizes the historical role played by the industrial revolution both on the demand and on the supply of skills. The accumulation of capital and the diffusion of new techniques during the process of industrialization made skills more valuable (demand). At the same time, income rose above the subsistence level, allowing families to invest more in human capital (supply). ${ }^{5}$ Hence, the reallocation of time toward human capital formation could be associated with a rise in income rather than with a decline in the marginal productivity of physical capital. The problem with this argument, however, is that as wages go up, the actual and the opportunity costs of education increase as well. Indeed, there are historical episodes suggesting that technological progress did not directly lead to more formal education. The industrial revolution brought about a considerable rise in wages for the British workers, who remained virtually illiterate until the second half of the 19th century. Easterlin's (1981) data show that a noticeable increase in British primary education occurred only until the second half of the 19th century, almost a century after the

\footnotetext{
${ }^{3}$ Similarly, computer science departments have boomed since the arrival of information technologies. In medicine, clinical simulations became part of medical doctor training after the introduction of new medical instruments, such as part-task simulators, cardiovascular systems, and multimedia programs. (Bradley, 2006). A further noticeable innovation in medical education is associated with the dissemination of videoscopic imaging techniques (Borst, 2001).

${ }^{4}$ Diamond (1997) and Aiyar et al. (2008) discusses historical episodes of technological regressions in preindustrial societies. But temporary setbacks have not stopped the process of knowledge creation. Although during the Middle Ages, Greek and Roman architecture was no longer in use, the knowledge remained embodied in artifacts, allowing Renaissance architects- most notably Brunelleschi - to learn from them.

${ }^{5}$ See Galor (2005) for a comprehensive discussion.
} 
onset of the Industrial Revolution. ${ }^{6}$

Another line of research links the larger investment in human capital with the rise in life expectancy (see the pioneering work by Ben-Porath (1967), as well as Boucekkine, de la Croix and Licandro (2002, 2003), Cervellati and Sunde (2005), Soares (2005)). Although the time series of longevity and education have been moving in lock-step since the middle of the nineteenth century, the recent work by Acemoglu and Johnson (2006) finds no effect of life expectancy on schooling, suggesting a spurious serial correlation between education and longevity. Furthermore, Hazan and Zoabi (2006) argue that, in principle, parents' choices about their children's levels of education may not be affected by longevity, for this raises not only the return on education but also that on fertility. Consequently, parents may be tempted to increase the future stream of wages of the household by having more children rather than investing more on their children's education.

From a methodological point of view, this paper generalizes existing growth models in which income expansion is driven by investment both in innovation and education. Arnold (1998), Funke and Strulik (2000), and Lloyd-Ellis and Roberts (2002) propose models that merge the view that the growth of modern economies is based on the accumulation of human capital (Uzawa (1965), Lucas (1988), and Rebelo, (1991)) with the view that emphasizes R\&D investments (Romer (1990), Grossman and Helpman (1991), and Aghion and Howitt (1992)). Here, I go one step further and allow the education sector to benefit directly from the knowledge generated by the innovation sector. ${ }^{7}$ Kosempel (2004) also links long-run stylized facts with features of the transitional dynamics of a growth model with two engines of growth. Still, in Kosempel (2004) the saving rate is exogenous and firms allocate a fixed fraction of output to research and development, whereas in my economy both variables are included in the list of choice variables. Enlarging the set of choices in this direction allows me to highlight a substitution effect between innovation and education times, and to see the response of the interest rate to changes in preferences and to technological shocks. My analysis also bears a resemblance to Acemoglu and Guerrieri (2008), and Kongsamut, Rebelo, and Xie (2001) in that I try to account for a major structural change - the diversion of resources to the school sector - in an economy characterized by the constancy of key macroeconomic

\footnotetext{
${ }^{6}$ In the first phase of the Industrial Revolution, literacy was generally higher in rural areas than in industrial towns (Kirby 2003, p.116), and educators found it difficult convince parents employed in industry that their children would benefit from schooling (Stephens, 1998, p. 19). Of course, some human capital formation was going on in the UK during the industrial revolution. The British strategy, however, was to learn by doing. This worked well enough as long as technology remained an accretion of improvements and invention based on known techniques (Landes, 1998, Ch. 18).

${ }^{7}$ In Lloyd-Ellis and Roberts (2002), disembodied knowledge is assumed to be proportional to the stock of human capital of an earlier generation, whereas here the behavior of human capital and public knowledge emerges from the model's dynamics.
} 
variables known as Kaldor facts, such as the output-capital ratio, the share of labor income, the interest rate, and the growth rate of output. Nevertheless, the Kaldor's facts here are reproduced as features of the transitional dynamics of an economy that tends towards a balanced growth path rather than as those of a nonbalanced growth economy. This paper also relates to one insight of Nelson and Phelps (1966): the return to education is greater in technological dynamic economies. ${ }^{8}$ It departs from the Nelson and Phelps framework because the return on education is not a function of the gap between the technological frontier and the technology used in production, but rather of the menu of technologies. Their approach is useful when studying contemporary economies at different stages of development, but it is more problematic in an historical perspective, for it is difficult to assess whether such a gap was smaller a century ago - implying low returns on education - than it is today.

The rest of the paper is organized as follows. Section 2 presents the model. Section 3 defines the competitive macroeconomic equilibrium. Section 4 derives a reduced-form dynamic system to describe the macroeconomic equilibrium. Section 5 defines the balanced growth path and illustrates how this is sensitive to variations in key parameters. Section 6 linearizes the system around the steady state and studies its properties. Section 7 describes the adjustment process of the system when it is hit by a positive technological shock, by a negative shock to physical and human capital, and by a sudden increase in public knowledge. Section 8 undertakes a calibration exercise to investigate whether the dynamics generated by the model are broadly consistent with the historical rise of the education sector, and with other key macroeconomic long-run U.S. time series. Section 9 concludes. The conditions for the existence of a balanced growth path are reported in the appendix.

\section{The model}

The economy is populated by infinitely-lived individuals of size 1 . There is no population growth. Each individual is endowed with one unit of time that he allocates between three types of activity: final good production $\left(u_{P}\right)$, education $\left(u_{E}\right)$, and innovation $\left(u_{I}\right)$. Thus, the following constraint holds:

$$
1=u_{P}+u_{E}+u_{I}
$$

Final Good Production. The flow of final good is given by

$$
y=z k_{1}^{\alpha_{1}} k_{2}^{\alpha_{2}}\left(h u_{p}\right)^{1-\alpha_{1}-\alpha_{2}}
$$

\footnotetext{
${ }^{8}$ The literature has emphasized a different insight of the Nelson and Phelps' contribution: the conjecture that education helps reduce the gap between the technological frontier and the actual one. Benhabib and Spiegel (2005) summarize empirical attempts to test this hypothesis.
} 
where $z$ is a positive constant, $h$ denotes the level of skills, $k_{1}$ is the service of physical capital, and $k_{2}$ is an aggregate measure of intermediate inputs, namely $k_{2}=\left[\int_{0}^{n} x_{j}^{\gamma} d j\right]^{1 / \gamma}$, where $x_{j}$ denotes the quantity of intermediate good $j$, and $\gamma$ regulates the elasticity of substitution between intermediates. There are $n$ such intermediates that can be used for production. The elasticity of output with respect to the two types of physical capital are given by $\alpha_{1}$ and $\alpha_{2}$. Let $r$ be the rental price of $k_{1}, p_{j}$ be the price of $x_{j}$, and $w$ be the wage rate of one unit of human capital. The demand schedule for the three inputs is:

$$
\begin{gathered}
r=\alpha_{1} \frac{y}{k_{1}}, \\
p(j)=\alpha_{2} \frac{y}{k_{2}^{\gamma}} x_{j}^{\gamma-1},
\end{gathered}
$$

and

$$
w=\left(1-\alpha_{1}-\alpha_{2}\right) y /\left(h u_{P}\right),
$$

respectively. The price of the final good is normalized to one.

Intermediate Goods. Contrary to physical capital, intermediate goods are embodied in the final output. One unit of intermediate input is obtained by means of one unit of final output. There are no fixed costs. Profit maximization leads to the same monopolistic competition price, $p_{j}=p=1 / \gamma$, for all $j \in[0, n]$, and to a symmetric demand of good $j$ i.e. $x_{j}=x$, for any $j \in[0, n]$. It also implies that $k_{2}=n^{1 / \gamma} x$. Therefore, the demand for an intermediate input and the intermediate producer's profit, $\pi$, can be expressed as a function of final output: $x=\alpha_{2} \gamma y / n$ and $\pi=(1-\gamma) \alpha_{2} y / n$. As a result, Eq. (2) simplifies to

$$
y=\tilde{z} k_{1}^{\alpha_{1} /\left(1-\alpha_{2}\right)} n^{(1 / \gamma-1) \alpha_{2} /\left(1-\alpha_{2}\right)}\left(h u_{p}\right)^{\left(1-\alpha_{1}-\alpha_{2}\right) /\left(1-\alpha_{2}\right)},
$$

where $\tilde{z}=z^{1 /\left(1-\alpha_{2}\right)}\left(\alpha_{2} \gamma\right)^{\alpha_{2}}$.

Education. The formation of human capital is given by

$$
\dot{h}=b u_{E} h^{\tilde{\phi}} n^{\phi},
$$

where $b>0$ is a learning parameter, $u_{E}$ is learning time, $n$ is an index that captures the stock of public knowledge, assumed to be proportional to the menu of technologies, and $h$ is human capital. The parameters $\phi$ and $\tilde{\phi}$ are the elasticities of the flow of human capital to the stock of public knowledge and to the stock of human capital respectively. Both parameters are smaller than one. Typically the skills acquired through schooling are a function of the time spent in school and a positive externality from investment made in knowledge by previous generations. This is for instance the case in Uzawa (1965), Lucas (1988), Stokey (1991), Bils and Klenow (2000), Becker et al. (1990). To emphasize that knowledge acquisition is a social learning process Tamura (1991) introduces an additional 
externality in the individual's learning function that is represented by the average human capital of the population. Here, I focus on the greater opportunities associated with the expansion of the frontier knowledge rather than with the knowledge of the typical individual. Of course, if the set of public knowledge and the average level of human capital expand in the same proportion the alteration of the education function proposed here would not add much to the analysis. Although this is a reasonable simplification when the analysis is conducted on a balanced growth path (see Lloyd-Ellis and Roberts (2002)), public knowledge and average human capital do not need to go hand in hand. The scientific revolution of the seventeenth century and the advances in chemistry, biology, medicine and other areas that occurred during the Industrial Revolution have led to a great expansion of the set of public knowledge, but, arguably, the skill level of the working class has improved at a much slower pace.

Innovation. An individual with human capital $h$ that spends $u_{I}$ of his or her time working as an innovator generates a flow of innovation

$$
\dot{n}=\theta u_{I} h^{\tilde{\beta}} n^{\beta},
$$

where $\theta>0$, whereas $\beta$ and $\tilde{\beta}$ are non-negative and smaller than one. The above specification allows to obtain some of the existing models as special cases (for a review see Jones, 1999, 2005, and Klenow and Rodriguez-Clare, 2005). In particular, the functional form is very close to the non-scale growth model of Jones (1995) (see also Arnold, 2006), except that here the existence of two engines of growth requires the additional constant-return-to-scale restriction for a balanced growth path to exist. In Romer (1990) $\beta=1$ and $h$ is constant (a change in human capital would be captured by a variation in $\theta$ ). Conversely, in Grossman and Helpman (1991, Ch. 3.1) $\beta=0$ - no dynamic R\&D spillovers.

Households. The aim of the individual is to find a set of control functions $\left(c(t), u_{P}(t), u_{E}(t), u_{I}(t)\right)$ that maximizes the utility function $\int_{0}^{+\infty} u(c(t)) \exp (-\rho t) d t$, where $t$ denotes time, $c(t)$ is consumption at time $t$, and $\rho$ represents the subjective discount rate. The constraints are: the dynamic asset budget constraint $\dot{a}(t)=w(t) u_{P}(t) h(t)+r(t) a(t)+\dot{n} v(t)-c(t)$, Eqs. (1), (7) and (8), and two initial conditions on assets and human capital (there are no profits distributed to households). The variable $v(t)$ represents the claim for establishing a capital good firm, $a(t)$ indicates the per capita amount of assets, and $r(t)$ denotes the real interest rate. The first term on the right of the equality is labor income, the following term captures interest income, and the third one accounts for the entrepreneurial gain of establishing new intermediate good firms. I formulate the optimization problem as a Hamiltonian system that includes the dual variables $\lambda$ and $\mu$ - the shadow values associated with the asset budget constraint and (7) respectively. Assuming $u(c)=\left(c^{1-\sigma}-1\right) /(1-\sigma)$, where $\sigma>0$ is a parameter that captures the inverse of the intertemporal elasticity of substitution in consumption, the 
current value Hamiltonian for the household is

$H\left(a, h ; \lambda, \mu ; c, u_{E}, u_{I}\right)=\frac{c^{1-\sigma}-1}{(1-\sigma)} e^{-\rho t}+\lambda\left[w\left(1-u_{E}-u_{I}\right) h+\theta u_{I} n^{\beta} h^{\tilde{\beta}} v+r a-c\right]+\mu b u_{E} h^{\tilde{\phi}} n^{\phi}$,

where I used (1) to replace $u_{P}$, and dropped the time variable $(t)$. The shadow values $\lambda$ and $\mu$ evaluate increments of income and of human capital in units of today's indirect utility, respectively. Hence, the objective is to find a four-dimensional vector $(\lambda, \mu, a, h)$ that maximizes $H(\bullet)$. Below, I report the first-order necessary conditions for an interior solution and the conditions prevailing in a corner solution when $u_{I}$ or $u_{E}$ are equal to zero.

The condition with respect to $c$ is

$$
c^{-\sigma} e^{-\rho t}=\lambda
$$

and the one with respect to $u_{I}$ is

$$
w h=\theta n^{\beta} h^{\tilde{\beta}} v \text { and } u_{I}>0
$$

or

$$
w h>\theta n^{\beta} h^{\tilde{\beta}} v \text { and } u_{I}=0 .
$$

Likewise, the optimal condition on $u_{E}$ is

$$
\lambda w h=\mu b n^{\phi} h^{\tilde{\phi}} \text { and } u_{E}>0
$$

or

$$
\lambda w h>\mu b n^{\phi} h^{\tilde{\phi}} \text { and } u_{E}=0 .
$$

If $u_{E}>0$, the following condition must also hold on the optimum trajectory:

$$
-\dot{\mu}=\lambda w\left(1-u_{E}-u_{I}\right)+\tilde{\beta} \lambda \theta u_{I} n^{\beta} h^{\tilde{\beta}-1} v+\tilde{\phi} \mu b u_{E}(h)^{\tilde{\phi}-1} n^{\phi} .
$$

Finally, the condition on assets is

$$
-\dot{\lambda}=\lambda r
$$

In sum, Eqs. (9), (10a), (11a), (12), and (13), along with two transversality conditions $\left(\lim _{t \rightarrow+\infty} \lambda(t) a(t)=\lim _{t \rightarrow+\infty} \mu(t) h(t)=0\right)$ represent the necessary conditions of the household's dynamic problem with initial endowment $\left(a_{0}, h_{0}\right)$. They are also sufficient conditions if $H(\bullet)$ is jointly concave in $(a, h)$, when (9), (10a), and (11a) hold. ${ }^{9}$

\footnotetext{
${ }^{9}$ This is known as the Arrow theorem. See Kamien and Schwartz (1994), p. 222. To verify the concavity, insert Eqs. (9), (10a) and (11a) into $H(\bullet)$, which becomes $\kappa+\tilde{\lambda} \theta n^{\beta} h^{\tilde{\beta}} v+\tilde{\lambda} r a$, where $\kappa=\frac{\tilde{\lambda}^{\sigma /(1-\sigma)}-1}{(1-\sigma)} e^{-\rho t}-$ $\tilde{\lambda}^{\sigma /(1-\sigma)}$ and $\tilde{\lambda}=\lambda e^{-\rho t}$. Clearly, the previous expression is concave in $a$ and $h$.
} 


\section{General equilibrium}

Given the initial stocks of human capital, $h(0)$, physical capital, $k(0)$, and public knowledge, $n(0)$, a dynamic competitive equilibrium in this economy is defined as a path of prices $\{r(t), w(t), p(t)\}_{t=0}^{+\infty}$ and quantities $\left\{k_{1}(t), h(t), x(t), n(t), v(t), a(t), u_{E}(t), u_{I}(t), u_{p}(t)\right\}_{t=0}^{+\infty}$, that satisfies the following conditions (for brevity I will omit the support for $t$ ):

1. The representative household chooses the path $\left\{c(t), u_{E}(t), u_{I}(t), u_{p}(t), a(t)\right\}$ that maximizes his present discounted value of utility, given the path of prices $\{r(t), w(t)\}$, the value of intermediate firms, $v(t)$, public knowledge, $n(t)$, the initial endowment of assets, $a(0)$, and human capital, $h(0)$ (that is, Eqs. (1), (7), (8), (9) through (13), and the two transversality conditions hold).

2. Each intermediate producer, $j$, sets a price $p_{j}(t)$ to maximize profits, given the demand function for $x_{j}(t)$.

3. Final goods producers choose the amount of quality-adjusted labor, $h(t) u_{p}(t)$, physical capital $k_{1}(t)$, and intermediate goods $x_{j}(t)$, for $j \in[0, n]$, so as to maximize profits (Eqs. (3)-(5)), given the input prices $\{r(t), w(t), p(t)\}$ and the available production technology (Eq. 2).

4. At any point in time, the markets for final goods, intermediate goods, labor, capital, and financial assets clear.

One can verify that the market clearing conditions, the firms' optimization equations, and the households budget constraints are consistent with the aggregate law of motion for physical capital: ${ }^{10}$

$$
\dot{k}_{1}=y-c-n x .
$$

\section{Reduced dynamic system}

This section describes the dynamics of the competitive equilibrium when both the innovation sector and the education sector are present $\left(u_{I}>0\right.$ and $\left.u_{E}>0\right)$. In order to obtain a system that convergences to a balanced growth path (BGP), to be defined shortly, the following two restrictions are imposed: i) $\phi g_{n}=(1-\tilde{\phi}) g_{h}$; ii) $(1-\beta) g_{n}=\tilde{\beta} g_{h}$. For the sake of simplicity, I will assume that $\tilde{\phi}=1-\phi$ and $\tilde{\beta}=1-\beta$.

\footnotetext{
${ }^{10}$ The household budget constraint is $\dot{a}(t)=w(t) u_{P}(t) h(t)+r(t) a(t)+\dot{n} v(t)-c(t)$. For brevity the time variable $t$ is dropped. By definition $a=k_{1}+n v$, therefore $\dot{a}=\dot{k}_{1}+\dot{n} v+n \dot{v}$. Plugging these two equations into the budget constraint, this becomes: $\dot{k}_{1}+n \dot{v}=w u_{P} h+r\left(k_{1}+n v\right)-c$. By using the firms' demand functions (3) and (5) the last equation modifies to $\dot{k}_{1}+n \dot{v}=\left(1-\alpha_{2}\right) y+r n v-c$. This expression, combined with arbitrage condition $\dot{v}=-\pi+r v$, yields $\dot{k}_{1}=\left(1-\alpha_{2}\right) y+n \pi-c$. By recalling that $\pi=(1-\gamma) \alpha_{2} y / n$ we get $\dot{k}_{1}=\left(1-\gamma \alpha_{2}\right) y-c$. Finally, since $x=\alpha_{2} \gamma y / n$, it follows that $\dot{k}_{1}=y-c-n x$.
} 
Let $\chi \equiv c / k_{1}$ and $\psi \equiv \frac{h}{n}$. With this transformation, the competitive equilibrium can be expressed as a four-dimensional system in $\psi, \chi, r$, and $u_{P} \cdot{ }^{11}$

The behavior of the ratio $\psi$ is given by Eqs. (7) and (8):

$$
g_{\psi}=b u_{E}(\psi)^{-\phi}-\theta u_{I}(\psi)^{1-\beta}
$$

As for the behavior of $\chi$, notice that the resource constraint (14) can be written as

$$
g_{k_{1}}=\frac{\left(1-\alpha_{2} \gamma\right)}{\alpha_{1}} r-\chi
$$

and that the solution of the household problem yields $g_{c}=\frac{1}{\sigma}(r-\rho)$. Therefore,

$$
g_{\chi}=\left(\frac{1}{\sigma}-\frac{1-\alpha_{2} \gamma}{\alpha_{1}}\right) r+\chi-\frac{\rho}{\sigma} .
$$

The evolution of $r$ is linked to that of $y$. The reduced-form production function (6) implies that

$$
g_{y}=\frac{1-\alpha_{1}-\alpha_{2}}{1-\alpha_{2}}\left(g_{h}+g_{u_{P}}\right)+\frac{(1 / \gamma-1) \alpha_{2}}{1-\alpha_{2}} g_{n}+\frac{\alpha_{1}}{1-\alpha_{2}} g_{k_{1}} .
$$

This, combined with the time-log differentiated versions of Eqs. (3) and (5), and with Eq. (16), yields

$$
g_{r}=-\frac{1-\alpha_{1}-\alpha_{2}}{\alpha_{1}} g_{w}+(1 / \gamma-1) \frac{\alpha_{2}}{\alpha_{1}} g_{n},
$$

where the growth rate of $n$ is given in Eq. (8) and that of $w$ is derivable either from Eq. (20) or from Eq. (23) reported below.

Finally, we need to uncover the behavior of $u_{p}$. The labor market equilibrium condition (10a) implies that $g_{w}+\beta g_{h}=\frac{\dot{v}}{v}+\beta g_{n}$. Since $\frac{\dot{v}}{v}=r-\frac{\pi}{v}{ }^{12}$ and $w h^{\beta}=\theta n^{\beta} v$, it follows that $\frac{\dot{v}}{v}=r-\frac{1-\gamma}{1-\alpha_{1}-\alpha_{2}} \alpha_{2} \theta \psi^{1-\beta} u_{P}$. Consequently,

$$
r-g_{w}=\frac{1-\gamma}{1-\alpha_{1}-\alpha_{2}} \alpha_{2} \theta(\psi)^{1-\beta} u_{P}+\beta g_{\psi} .
$$

From Eqs. (3), (16), (18), and (19), one gets

$$
g_{u_{P}}=-\left(\frac{1-\alpha_{2}}{\alpha_{1}}\right) g_{w}+(1 / \gamma-1) \frac{\alpha_{2}}{\alpha_{1}} g_{n}+\frac{1-\gamma \alpha_{2}}{\alpha_{1}} r-\chi-g_{h} .
$$

\footnotetext{
${ }^{11}$ The dynamics of special cases in which $\beta$ or $\phi$ is zero or one are considerably simpler. Appendix B, posted on my webpage, briefly illustrates three of such cases and relates them to the extant literature.

${ }^{12}$ Assuming that monopoly power lasts forever, the value of an intermediate good firm $i$ at time $t$ is $v(i, t)=\int_{t}^{\infty} e^{-[R(s)-R(t)]} \pi(i, s) d s$, where $R(s)=\int_{0}^{s} r(\tau) d \tau$, and $r(\tau)$ is the instantaneous interest rate at time $\tau$. Hence,

$$
\partial v(i, t) / \partial t=-\pi(i, t)+\int_{t}^{\infty}\left[e^{-[R(s)-R(t)]} \pi(i, s)(\partial R(t) / \partial t)\right] d s
$$

which simplifies to $-\pi(i, t)+r(t) \int_{t}^{\infty}\left[e^{-[R(s)-R(t)]} \pi(i, s)\right] d s$, or more simply to $-\pi(i, t)+r(t) v(i, t)$.
} 


\section{Table 1: The Four-Dimensional System}

\begin{tabular}{l}
\hline$g_{\psi}=b u_{E}(\psi)^{-\phi}-\theta u_{I}(\psi)^{1-\beta}$ \\
$g_{\chi}=\left(\frac{1}{\sigma}-\frac{1-\alpha_{2} \gamma}{\alpha_{1}}\right) r+\chi-\frac{\rho}{\sigma}$ \\
$g_{r}=-\frac{1-\alpha_{1}-\alpha_{2}}{\alpha_{1}} g_{w}+(1 / \gamma-1) \frac{\alpha_{2}}{\alpha_{1}} g_{n}$ \\
$g_{u_{P}}=-\left(\frac{1-\alpha_{2}}{\alpha_{1}}\right) g_{w}+(1 / \gamma-1) \frac{\alpha_{2}}{\alpha_{1}} g_{n}+\frac{1-\gamma \alpha_{2}}{\alpha_{1}} r-\chi-g_{h}$
\end{tabular}

Note. The table contains the equations that describe the four-dimensional system in $r, \psi, \chi$, and $u_{P}$. The variables $g_{h}, g_{n}$, and $g_{w}$ are to be replaced with expressions derived from (7), (8), and (20), whereas $u_{I}$ and $u_{E}$ are eliminated through (1) and (24).

Notice that (15), (17), (19), and (21) form already a four-dimensional system in $r, \psi, \chi$, and $u_{P}$, provided that $g_{n}, g_{h}$, and $g_{w}$ are replaced with expressions derived from (7), (8), and (20). Still, the system also contains $u_{E}$ and $u_{I}$; therefore two additional relationships are needed. One is provided by the time constraint (1). The other is obtained by exploiting the link between the two shadow values $\lambda$ and $\mu$. By inserting Eq. (11a) into Eq. (12), and noting that $v=w h^{\beta} / \theta n^{\beta}$ we get

$$
-\dot{\mu} / \mu_{t}=b(\psi)^{-\phi}\left(1-\phi u_{E}-\beta u_{I}\right)
$$

This, combined with the log-differentiated version of the Eq. (11a), yields

$$
r-g_{w}=b(\psi)^{-\phi}\left(1-\phi u_{E}-\beta u_{I}\right)+\phi\left(g_{h}-g_{n}\right)
$$

Because the left-hand side of this equation and that of Eq. (20) are the same, it follows that

$$
(\beta-\phi)\left(g_{h}-g_{n}\right)=b(\psi)^{-\phi}\left(1-\phi u_{E}-\beta u_{I}\right)-\frac{1-\gamma}{1-\alpha_{1}-\alpha_{2}} \alpha_{2} \theta(\psi)^{1-\beta} u_{P}
$$

For a given $u_{I}$ and $\psi$, this relationship pins down the value of $u_{E}$.

Table (1) summarizes the fourth-order dynamic system over the space $\left(r, \psi, \chi, u_{P}\right) .{ }^{13}$

\section{Balanced growth path and comparative dynamics}

The balanced growth path is defined as an equilibrium in which consumption, output, physical capital, human capital and public knowledge grow at a steady rate (but not necessarily at the same rate), and in which the interest rate and the fraction of time allocated to education and innovation are constant. By setting the left-hand-side of Eqs. (15), (17), (19), (21),

\footnotetext{
${ }^{13}$ One would also need to verify that the transversality conditions hold. Alternatively, one could compute the steady state and make sure that the equilibrium trajectory tends to that point (see Kamien and Schwarts, 1991, p.174). Here, it is easy to follow the latter route.
} 
and (24) to zero and eliminating $g_{w}$ through Eq. (20) one obtains a system whose solution represents the steady state of six stationary variables. Appendix A derives the conditions for such an equilibrium to exist.

To uncover some basic mechanisms of the model, I explore how the steady state reacts to variations in technology and preferences. The exercise is done through a number of simulations - it would be quite cumbersome to carry it out analytically. The starting values of the parameters are reported in Table (2): They imply an interest rate of 5\%, an $1.5 \%$ annual rate of output growth, and a labor income share - calculated from Eq. (6) - of 0.7 (see Table (3)). The main results of the experiments are summarized in Table (4).

Preferences. An economy with a high discount rate $(\rho)$ has a relatively low saving rate. The second column of Table (4) shows a positive sign associated with $\chi$ - which is inversely related to the interest rate. In a broad sense, $u_{E}$ and $u_{I}$ are also part of the saving decision. A low level of broad saving implies slow output growth and high interest rate (because of the relatively low level of physical capital). An increase in $\sigma$-the inverse of the intertemporal elasticity of substitution - yields similar qualitative results.

Innovators' productivity $(\theta)$. A rise in this parameter clearly has a positive effect on $u_{I}$. As a result, the economy innovates more and accumulates more public knowledge. Since this is a free input for the education sector, individuals will also spend more time in school. Nevertheless, the sign associated to $\psi$ is negative, indicating that human capital does not increase as much as public knowledge. Because both innovation and education time increase, output growth unequivocally goes up. Both the interest rate and $\chi$ also increase as resources are shifted away from physical capital accumulation.

Quality of Education (b). An exogenous enhancement of the quality of education induces people to spend longer stretches of time in school. As a result, individuals stock up more human capital. As this leads to greater productivity in the final goods sector, at least when the displacement effect on physical capital is limited, it eventually shifts the demand for intermediate goods upward. The prospective of higher future profits causes an appreciation in the value of intermediate firms. The higher return on innovation activities leads to a higher $u_{I}$. The economy grows faster because both $u_{I}$ and $u_{E}$ rise. Innovation and education displace investments in physical capital; therefore, the positive signs associated with $\chi$ and $r$.

The elasticity $(\phi)$. If the elasticity of education to public knowledge increases, the elasticity to human capital declines. Consequently, human capital loses value, for it plays a more modest role in promoting human capital formation in the future. The lower skill level of the work force diminishes the demands for new products, leading to a reduction in $u_{I}$. The negative sign associated with $\psi$ indicates that the decline of human capital is relatively greater than that of public knowledge. Clearly, the economy grows at a slower pace. Finally, 
the interest rate and $\chi$ also decline because more resources are diverted into physical capital investments.

The elasticity $(\beta)$. The same comment I made for $\phi$ applies to $\beta$, with the only caveat that $\psi$ now moves in the opposite direction.

Output elasticity to capital $\left(\alpha_{1}\right)$. Since output is produced with a constant return to scale technology, when $\alpha_{1}$ rises the output elasticity to labor, adjusted for skills, drops. The outcome of such a variation is ambiguous. On the one hand, human capital is less valuable in production. But this negative effect is compensated for by the greater productivity of physical capital. When departing from low (high) values of $\alpha_{1}$ the physical-capital effect (human-capital) dominates and $u_{E}$ rises (drops). $u_{I}$ is only indirectly affected by the shock (through the market variation of firms values), and its behavior is qualitatively similar to that of $u_{E}$. Physical capital becomes relatively more important; therefore, the signs associated with $r$ and $\chi$ are negative.

Output elasticity to intermediate goods $\left(\alpha_{2}\right)$. Some of the consequences of a rise in $\alpha_{2}$ associated with the labor share are similar to those just illustrated for $\alpha_{1}$, though here the quantitative impact on $u_{I}$ is greater because the indirect effect generated by human capital comes on the top of a direct one. Furthermore, when $\alpha_{2}$ is high, homogeneous capital loses ground relative to intermediate goods. This explains the positive relationship linking $\alpha_{2}$ both to $r$ and $\chi$.

The elasticity across intermediate goods $(\gamma)$. When the parameter $\gamma$ increases, the monopoly power of intermediate firms diminishes. Clearly $u_{I}$ drops, but the effect on education is ambiguous because this partly replaces innovation. Thus, if the cutback on innovation substantially reduces the development of public knowledge, the return to education declines and so does education time. In other words, the model generates an inverted-U relationship between schooling time and $\gamma$.

\section{Linearization around the steady state}

In order to gain further insights into the dynamics of the model, I will study the economy's adjustment process around the steady state. I will focus on the dynamics of four key variables $r, \psi, u_{P}$, and $\chi$, because once their behaviors are known, the patterns of $u_{E}$ and $u_{I}$ can be easily obtained through (1) and (24). The fourth-order dynamic system is given by Eqs. (15), (17), (19), and (21) provided that the expressions $g_{h}, g_{n}$, and $g_{w}$ are replaced according to Eqs. (7), (8), and (20). The system consists of two jumpy variables, $u_{P}$ and $\chi$, and two predetermined variables, namely, the human capital-knowledge ratio, $\psi$, and the interest rate $r$. The interest rate is proportional to the output-capital ratio (see Eq.(3)); this, in turn, is a function of the choice variable $u_{P}$. Since $u_{P}$ is already part of the list of jumpy 
variables, $r$ will be considered a state-like variable. ${ }^{14}$ The distinction between jumpy and predetermined variables is relevant for establishing the local saddle-stability properties of the systems around the steady state. Because there are two predetermined state variables, $r$ and $\psi$, with initial value $r(0)$, and $\psi(0)$, this type of stability requires that the linearized system in the neighborhood of the steady state be a saddle with two-dimensional stable and two-dimensional unstable manifolds. A few simulations reveal the following patterns.

If $0<\phi<\beta<1$, the Jacobian may have two positive and two negative eigenvalues, all real (case 1.a), or two real and positive eigenvalues and two complex conjugate eigenvalues with negative real parts (case 1.b).

If $0<\beta<\phi<1$ we have two situations: one eigenvalue is negative and real and three are real and positive (2.a); or one eigenvalue is negative and real, a second one is positive and real, and the other two are complex and conjugates (case 2.b).

The Stable Manifold Theorem guarantees, in cases (1.a) and (1.b), the existence of a twodimensional stable manifold and a two- dimensional unstable manifold (Palis and DeMelo, 1982). In situation (1.b), the system generates oscillating dynamics that are difficult to match with data. In cases (2.a) and (2.b) the system is unstable because the stable manifold has one dimension against two predetermined variables. Therefore, I will continue the exposition assuming that the parameters are in a set compatible with case (1.a). Notice that the system does not give rise to indeterminacy, a situation with three negative eigenvalues. This scenario is likely to appear if the assumption of constant return to scales in one of the three sectors is relaxed (see Benhabib and Perli, 1994)..$^{15}$

Fig. (1) shows that every trajectory starting from any point in the positive quadrant $(r-\psi)$ converges to the node $\left(r^{*}, \psi^{*}\right)$. The $\dot{r}=0$ and $\dot{\psi}=0$ loci have a negative slope - a feature that prevailed in all simulations, except for low values of $\beta$ and $\phi$ when the slope of the $\dot{r}=0$ line is positive.

\section{Simulations}

Next, I study how an economy, on its balanced growth path, responds to shocks to productivity, knowledge, and to human and physical capital. To this end, following a backward induction technique, I numerically build a two-dimensional manifold containing the set of solutions of the four dimensional dynamic system. The basic idea is to make a small step away from the steady state in all possible directions along the linearized stable manifolds

\footnotetext{
${ }^{14}$ One could build a dynamic system in which the state variable is the interest rate net of $u_{p}$, but the graphical illustrations would be less intuitive.

${ }^{15}$ The advantage of indeterminacy in this context would be that the model might explain why two countries with similar initial condition on the interest rate and $\psi$, choose distinct patterns of consumption, education, and innovation.
} 
and then, from there, to integrate the system backward (Brunner and Strulik (2002)). ${ }^{16}$ The procedure yields trajectories of the type depicted in Fig. (1).

\subsection{Productivity shock}

Imagine the final good sector experiences a positive productivity shock ( $z$ jumps up), while the economy is on its balanced growth path. Such a shock indicates that the production process has improved for reasons other than input variety expansion or skill accumulation - for instance, process innovation. Since $z$ does not have an immediate effect on $\psi$, the economy's position in Fig. (1) is $\left(\psi^{*}, r^{\prime}\right)$, where $r^{\prime}>r^{*}$ (the interest rate jump already accounts for adjustment of the choice variables). After the shock, the interest rate declines monotonically towards $r^{*}$, whereas $\psi$ follows a U-shaped pattern. The behavior of $\psi$ clearly depends on that of $u_{E}$ and $u_{I}$. The time profile of all four variables is depicted in Fig. (2). This shows that initially $u_{E}$ drops and $u_{I}$ rises. Subsequently, the quality of education goes up quite rapidly - driven by the expansion of public knowledge, $u_{E}$ increases, and the fall of $\psi$ is reversed. The relationship between initial variations in $r, z$, and $u_{P}$ are derived from Eq. (6) as follows:

$$
\hat{z}=\left(1-\alpha_{2}\right) \hat{r}-\left(1-\alpha_{1}-\alpha_{2}\right) \hat{u}_{p}
$$

where $\mathrm{a}^{\wedge}$ on the top of a variable denotes percentage deviation from the steady state. In this derivation $\psi$ is kept constant. Row (1) of Table (5) reports the immediate response of $r, u_{p}, u_{E}, u_{I}, w, c, \chi$, and of the shadow value of human capital relative to that of income, $\mu / \lambda$. The greater productivity of physical capital leads to an immediate increment of the interest rate, of labor productivity and of wages. In addition, because time is shifted from education into production, the interest rate climbs up even further. The new optimal balance between accumulation of physical assets and of human capital is captured by the ascent of the ratio $\mu / \lambda$, indicating that human capital is becoming scarce relative to financial assets. The increased productivity generates also a wealth effect, leading to an upward adjustment in consumption.

In sum, the short-run consequences of a positive technological shock are: Faster introduction of new capital goods, acceleration of final goods production, reduction in schooling time, and surge in consumption.

\subsection{Destruction of physical capital}

An overnight destruction of physical capital also causes a sudden upward jump of the interest rate. The ratio $\psi$ is not initially affected by the shock. The adjustment process of

\footnotetext{
${ }^{16}$ The equations are numerically integrated by Matlab 6.5 with the forth-order Runge-Kutta solution method (the error of tolerance is set to $10^{-6}$ ).
} 
$r, u_{p}, u_{E}, u_{I}, w, c$, and $\chi$ resulting from such a negative shock is qualitatively similar to that described for a positive technological shock, and can be followed through the same Figs. (1) and (2), ${ }^{17}$ although, as it will be clarified shortly, some of the underlying mechanisms differ. Eq. (6) implies that the relationship among initial deviations from the steady state is

$$
\hat{k}_{1}=\hat{u}_{p}-\frac{1-\alpha_{2}}{1-\alpha_{1}-\alpha_{2}} \hat{r} .
$$

Row (2) of Table (5) summarizes the immediate response of the economy to a negative one percent shock on $k_{1}$. As a result of a dip in labor productivity, wages drop by about half a percent. Labor income does not diminish as much though, because production time, $u_{P}$, increases. Why do $w$ and $u_{P}$ move in opposite directions? The answer lies in the behavior of the education sector. After the shock, the amount of human capital is too large relative to that of physical capital and financial assets. (In the last column of Table (5), the ratio $\mu / \lambda$ goes down by $0.46 \%$ ). Accordingly, it is optimal to slow down the accumulation of human capital. The time freed-up from education is split between innovation and production. Although consumption recedes, the dip is mitigated by the diversion of time into production and innovation, yielding a greater amount of income. The time devoted to education may go in either direction.

\subsection{Inflow of public knowledge}

The economy so far has been considered closed; therefore all the public knowledge is generated exclusively from domestic innovation. Nevertheless, knowledge may percolate from abroad (see Eaton and Kortum (1999) for a discussion).

The immediate response of the economy to an initial expansion of one percent of public knowledge is reported in Table (5), row (3). Thanks to the availability of a greater variety of tools, labor productivity and wages go up, inducing individuals to spend more time into the final goods sector. This inflow mitigates the increase in the marginal productivity of labor and of the wage rate, which goes up only by only half of a percentage point. The productivity of physical capital and the interest rate also rise. Since human capital becomes more valuable (the ratio $\mu / \lambda$ increases), more time is devoted to schooling. Nonetheless, the sudden expansion in the number of intermediate inputs reduces the value of newly formed domestic firms causing $u_{I}$ to slide. Finally, the boom in consumption is driven by the greater level of income.

The adjustment process towards the steady state is shown in Fig. (3). In terms of Fig. (1), the position of the economy after the shock is point E. During the transition, people

\footnotetext{
${ }^{17}$ Indeed, Fig. (2) represents the dynamics of the economy when it is perturbed by a one percent positive shock in $z$, or a negative shock on $k_{1}$ of $2.68 \%$.
} 
migrate back into the innovation sector as the stock market recovers from the sudden crisis: Firms expect that the greater amount of human capital will shift the demand for intermediate inputs, and raise the flow of monopoly profits. The boost in final production allows also an acceleration of physical capital formation. Indeed, over the transition, both $\chi$ and $r$ decline. The human capital-knowledge ratio follows a U-shape: At first the acceleration of human capital accumulation drags it down, but then the intensification of the innovation activity relative to schooling brings it up again.

\subsection{Destruction of human capital}

In this model, as individuals live forever, there is no depreciation of human capital. Nevertheless, government regulations or social norms may create barriers that limit people's abilities to use their current skills and knowledge. Furthermore, as Galor and Weil (2000) and Galor and Moav (2002) point out, sudden accelerations in $n$ may have a negative effect on human capital formation, because they render existing skills obsolete.

The initial response is reported in Table (5), row (4). The diminished quality of labor pushes down the productivity of capital. Time is reallocated from innovation and production into education, so as to remedy for the loss of human capital. The decline of human capital employed in production $\left(h u_{P}\right)$ causes a rise in the wage rate. Finally, consumption drops due to the decline in today's and future income. On the plane $(r-\psi)$ of Fig. (1) the economy jumps somewhere in region IV and follows a pattern that travels through region III. Consequently, the final piece of the adjustment process of the state-like variables is qualitatively similar to that of a positive shock on $n$.

\section{Calibration}

The objective of this section is to investigate whether the equilibrium dynamics generated by the model are broadly consistent with the development pattern of the U.S. economy since the onset of formal education - about the middle of the 19th century - by means of illustrative calibrations. I pick standard values for the preferences and technology parameters $z, \alpha_{1}, \alpha_{2}, \gamma, \theta, b, \sigma$, and $\rho$. Once their values is fixed, I run a grid-search in the unit interval for the pair $\phi$ and $\beta$ so as to find the combination that delivers time-patterns of key macroeconomic variables that resemble their actual time series counterparts. The constraint $\phi<\beta$ is imposed, for I am interested in a two-dimensional manifold set of solutions converging to the steady state $\left(r^{*}, u_{P}^{*}, \psi^{*}, \chi^{*}\right)$. 


\subsection{Data}

Education. The fraction of time spent in school, $u_{E}$, is estimated by taking the ratio between the average number of schooling years and life expectancy. The Department of Health and Human Services - henceforth DHHS - (2006) reports the average life expectancy in the United States beginning from 1850 for different age groups. For instance, the life expectancy in 1850 of 10- and 20-year-old white males were 48 and 40.1, respectively, whereas, in 2000, the corresponding figures were 65.4 and 55.7. On the basis of these data, I estimate that the life-span of the representative individual is about 59 (the average between 58 and 60.1) for the year 1850 and 75.5 for the year 2000. DHHS (2006) provides only two data points for the 19th century: 1850 and 1890. The frequency is at least every ten years from 1900 on. As concerns the duration of schooling, I rely on the recent estimates elaborated by Baier et. al. (2007). This study calculates the average years of schooling of the labor force in the U.S. on a 20-year interval, starting from 1840. Because the starting point and the frequencies of the two series do not coincide, some interpolation was needed to fill the19th century data points missing. Table (6) shows a snapshot of the data and of my estimates for $u_{E}$.

Output. The output of final goods, $y$, is matched with the per capita GDP time series elaborated by Maddison (2003). For the United States, this is available on an annual basis from 1870 onward, whereas, for the earlier part of the 19th century, it is available on a 10-year interval basis.

Interest Rate. Table IV of Barro (2006) shows that the real stock return in the United States for the 1880-2004 and 1954-2004 time periods are 0.081 and 0.089 respectively. The real bill return for the same two periods is 0.015 and 0.017 , respectively. Siegel (1998) calculates a return of $7 \%$ for the periods $1802-1997$, and $1871-1997$, and of $6.7 \%$ for the period 1913-1997 (see Table 8-1). Consequently, I calibrate the model in a way that during the transition the real interest rate is somewhere between these rates and roughly constant.

Consumption-Capital Ratio. Consumption and capital stock time series are drawn from the National Income and Product Accounts (NIPA) and from the Fixed Assets data. Both series are available from 1925 up to 2007 at the Bureau of Economic Analysis. ${ }^{18}$ The consumption-capital ratio, $\chi$, is matched with the ratio between non-durable consumption expenditures and the (net-cost) value of fixed assets. Both series are in current dollars.

Output-Capital Ratio. The denominator of the ratio is still fixed assets. The numerator is the NIPA GDP.

Total Factor Productivity. The plausibility of the model will also be judged against some simple growth accounting. Gordon (2000, Table 1) calculates the growth rate of total factor

\footnotetext{
${ }^{18}$ See NIPA Table 1.1.5 "Gross Domestic Product", and Table 1.1. "Current-Cost Net Stock of Fixed Assets and Consumer Durable Goods" that can be extracted from the Bureau of Economic Analysis data set available at http://www.bea.gov.
} 
productivity, GDP, capital, and labor for the U.S. economy from 1870 to 1996. Starting from Gordon's estimates, I compute the share of per capita output growth accounted for by total factor productivity and compare it with the corresponding ratio implied by the model (see Table (6)).

Data on knowledge. Unfortunately, there is no well accepted measurement of the stock of knowledge. Some consider patents as a good source of information for such an estimate. A time series of per capita patents on innovation shown in Jovanovic and Rousseau (2005) reveals a negligible activity before the Civil War and then a trendless behavior, with large upswings in the 1970s and 1990s, and a noticeable decline in the interwar period. But the poor patenting activity before the middle of the 19th century cannot be mistaken with technological stagnation. Indeed, at that time, by most accounts the first wave of Industrial Revolution was already completed. A second issue, emphasized by Graham and Mowery (2004), is that patenting may reflect phenomena other than mere innovation. They document, for instance, the important role of 'continuations' (procedural revisions of patent applications) in inflating the number of patents in the software industry in the 1980s and the 1980s. Hall and Ziedonis (2001) argue that defensive patenting greatly increased the filing of patents in the semiconductor industry. The approach used by Murrey (2003), who builds long-run paths of human accomplishments in arts and sciences, is a possible way around both types of issues. He draws information from 12 databases that describe inventions as far back as 800 B.C. and builds a filter to separate outstanding contributions from trivial ones. Unfortunately, the indices of human achievement stop at 1950, and the filter is based on scientists' evaluation of an invention rather on the contribution to productivity.

\subsection{Parameters}

My model economy is fully characterized by the nine parameters $z, \alpha_{1}, \alpha_{2}, \gamma, \theta, b, \phi, \beta, \sigma$, and $\rho$, and the two initial values $r(0)$, and $\psi(0)$. I choose the parameters as follows. First, I adopt the standard parameter value for the discount rate $(\rho=0.02)$, for the inverse of the intertemporal elasticity of substitution $(\sigma=2)$, and for the labor share $\left(\frac{1-\alpha_{1}-\alpha_{2}}{1-\alpha_{2}}\right)$, set to 0.7. The baseline value of $\alpha_{1}$ is 0.162 . This value allows the model economy to match, along the transition, a $5 \%$ interest rate - my target interest rate - and an output-capital ratio of about 0.33, observed in the data. The implied value for $\alpha_{2}$ is $0.46 .{ }^{19}$ The productivity parameter of the education sector $b=0.55$ - roughly the same as the one used by Lucas (1988). The innovation rate is strongly related to both $\theta$ and $\gamma$. I fix $\gamma=0.6$ (the elasticity across intermediate goods) and then choose $\theta$ so that, given the other parameters, the balanced

\footnotetext{
${ }^{19}$ These values are similar to those used in previous studies. See, for example, Acemoglu and Guerrieri (2008), Kongsamut et al. (2001), Eicher and Turnovsky (2001), Funke and Strulik (2000), and Ortigueira and Santos (1997).
} 
growth path of income is $1.5 \%$ - slightly smaller than the $1.8 \%$ secular U.S. per capita output rate of growth, here interpreted as a transitional phenomenon.

Two important parameters for my calibration are $\beta$ and $\phi .^{20} \mathrm{I}$ try to find the pair of values that is most likely to characterize the U.S. economy by matching the transitional dynamics of the model with the U.S. economic data in the last 150 years. From a grid search it turns out that the pair $\phi=0.4$ and $\beta=0.5$ gives a good fit.

\subsection{Results}

Table (2) summarizes my preferred values for the nine parameters. These are used in the benchmark calibration. Column (c) of Table (8) shows the value of seven macrovariables on the BGP. Fig. (4) depicts the time trajectories along the transitional dynamics of six of these variables: The share of education time $\left(u_{E}\right)$, capital-consumption ratio $(\chi)$, capital-output ratio $\left(y / k_{1}\right)$, the interest rate $(r)$, per capita output (in logs), and the ratio of total factor productivity (TFP) growth to output growth for about 150 years starting from the middle of the 19th century. Two measures of TFP are used: One considers only the contribution of technological progress, while the other includes the contribution of both education and innovation. The simulated pattern of each variable (dashed line) is compared against the U.S. time series (continuous line), when this is available.

From a visual inspection of Fig (4), a key aspect emerges: The schooling time rises from zero to about 18 percent and yet per capita output growth, the interest rate, the outputcapital ratio, and the consumption-capital ratio remain roughly constant. Because of the law of diminishing returns on physical capital, the transitional dynamics of neoclassical growth model are characterized by a marked decline in the interest rate (see King and Rebelo, 1993) and a deceleration in output growth. If human capital formation is added to the neoclassical model, the decline of the returns on physical capital is instrumental in triggering investment in education. ${ }^{21}$ In the model presented here, however, individuals spend more time in school not because investing in physical capital becomes less profitable, but because the return on education rises thanks to the growing stock of public knowledge. This is the main reason the

\footnotetext{
${ }^{20}$ Charles Jones' work and the non-scale innovation-based growth models suggest that $\beta$ should be less than one (see Jones, 2005, section 5). As concerns the educational sector, the standard Mincer specification for human capital formation has neither externalities from public knowledge nor any positive effects from the existing stock of human capital of the dynasty. Lucas (1988) assumes a strong externality for human capital ( $h$ is linear in $h$ ) but public knowledge is neglected. Bils and Klenow (2000) speculate that the human capital externality is much smaller than one, but again do not include public knowledge externalities.

${ }^{21}$ Interesting exceptions are Acemoglu and Guerrieri (2008) and Kongsamut et al. (2001). However, they analyze the unbalanced growth of two final goods sectors. Here, in contrast, the constancy of the growth rate of output and the relatively little variation of the interest rate are features of the transition towards the balanced growth path.
} 
transition occurs with a nearly constant interest rate, oscillating between 5 and 5.2 percent. The model also does a good job at capturing the level and time trend of all key variables. The per capita output grows at the same steady pace as the actual one, and education time closely parallels the secular upward trend of the time series. Both the capital-output ratio and the consumption-capital ratio are also consistent with the actual time series that starts from 1929. Direct evidence on the allocation of individual's time on innovation is not available yet. ${ }^{22}$ Here, I judge the consistency of the innovation time-patterns indirectly by means of growth accounting. The basic idea is to check whether the contribution of per capita output growth attributable to the Solow residual matches with the empirical one. The piecewise line in Panel E (see also Table 7) shows that, for most of the time periods considered, the contribution of the residual to output growth calculated with U.S. long-run data fluctuates between 0.4 and 0.9. A peak is recorded in the 1928-1950 time interval (1.4) and a exceptional low ratio (0.26) is displayed for the 1970s. The simulated trajectory stays fairly constant at about 0.8 .

A final characteristic deserves attention: the lack of acceleration of per capita output despite the rapid expansion of human capital. There are two forces that put a brake on such an acceleration. One is the drop of the fraction of production time - it is diverted into schooling; ${ }^{23}$ the other is the gradual decline of time allocated to innovation that causes a slow down in technological progress. The substitution of innovation for education is illustrated in Fig (4) Panel E. The fraction of labor productivity growth accounted for by innovation $\left(\frac{(1 / \gamma-1) \alpha_{2}}{1-\alpha_{2}} g_{n} /\left(g_{y}-g_{u}\right)\right)$, declines over time (bottom dashed line), whereas the joint contribution of innovation and education $\left(\left[\frac{1-\alpha_{1}-\alpha_{2}}{1-\alpha_{2}} g_{h}+\frac{(1 / \gamma-1) \alpha_{2}}{1-\alpha_{2}} g_{n}\right] /\left(g_{y}-g_{u}\right)\right)$ is roughly constant. Thus, a 'replacement effect' is taking place: less time is devoted to the adoption of new technologies, and more time is spent acquiring skills. Although this conjecture cannot be verified directly, it can be compared with the behavior of the ratio between U.S. total factor product growth and output growth, displayed in Panel E. The matching is not as good as ones discussed previously: the simulated TFP ratio shows a slight negative trend $(-0.006)$ whereas the actual one appears to be trendless.

Such a replacement effect resonates with Jones' (2005) evidence on the age trends among innovators. He finds a rise in the number of years devoted to doctoral studies as well as in the

\footnotetext{
${ }^{22}$ Studies on the allocation of time focus the attention on leisure versus work. Aguiar and Hurst (2007) and Ramey and Francis (2009) document a secular decline in the hours worked. Ramey and Francis (2009) attribute most of the decline to the rise of education. If one were to find that the time spent on the work place is relatively more intensive in innovation activities than that spent on leisure, these data would be consistent with the model's prediction. Future research, hopefully, will bring light on this point.

${ }^{23}$ This effect would not exist if the value added generated by the education sector were included in the computation of output.
} 
average age of inventors. In his analysis the expansion of technical knowledge increases the cost of education, because a more extended period is needed to absorb the greater amount of knowledge. Conversely, my model assumes that the rise of knowledge reduces the cost of education (per unit of human capital); yet it generates a replacement between innovation time and education time along the equilibrium path.

\section{Conclusion}

The main conjecture was that the expansion of public knowledge created the historical conditions for the onset and rise of formal education in modern societies. As the variety of technology expands, new opportunities to acquire knowledge appear and the expected returns on education increase, inducing individuals to spend a larger fraction of their lives to acquire human capital. As with prior studies, I see education as a form of investment that competes with physical capital formation, but my emphasis is on the increased efficiency of the education sector driven by the new windows of public knowledge, rather than on the declining marginal productivity of physical capital. I investigated the implications of these hypotheses by studying the transitional dynamics of a growth model with two complementary sources of long run growth (innovation and education), and verified their plausibility through calibration analysis. The transitional dynamics generated trajectories in which the interest rate and other key macroeconomic ratios remained flat despite the remarkable rise of education, bringing additional insights on how to reconcile Kaldor facts with fundamental structural changes. The dynamics of the model indicated that production time is only marginally affected by the rise of education, for most of the schooling time is subtracted from entrepreneurial activities. Therefore, as economies mature, more effort is devoted to exploit the stock of knowledge for productive purposes and less to expand it.

The paper leaves important questions open, some of which can only be assessed empirically. One is the extent to which public knowledge can trade-off the high returns of physical capital. The literature indicates remarkably high rates of returns on specific capital goods in developing countries. ${ }^{24}$ High returns do not seem to have kept education at bay altogether, but they may limit its expansion. A policy that promotes faster accumulation of physical capital would accelerate the transition towards higher levels of education. Yet, this may be a non-viable path, especially if the majority of the population is close to a minimum level of consumption. A faster alternative suggested by the model is the rapid expansion of public knowledge through the adoption of foreign technologies, as long as the knowledge that these

\footnotetext{
${ }^{24}$ Udry and Anagol (2006), for instance, estimate that the return to capital in Ghana's informal sector is $60 \%$. Double-digit returns have been found in numerous other papers that focus on developing countries. For a summary see Banerjee and Duflo (2005, p. 479-484).
} 
technologies embody can be studied; that is, it can be transformed into human capital.

A related aspect that would need further examination is the set of conditions that would allow the education sector to have the greatest possible access to public knowledge. The model did not make a distinction between what is known and what is taught in schools. Presumably, only a fraction of what is known is subject to systematic teaching in schools. In reality, higher educational institutions seem to compete fiercely with each other by offering new curricula that impart instructions in emerging fields or at the intersection of existing fields. The outcome of such competition has important dynamic consequences: The great expansion of schools in computer science in the 1980s and 1990s is an example of educational innovation inspired by the dissemination of information technology. Similarly, the financial innovation of the late 1980s was followed by a proliferation of programs in finance. Arguably, the former type of educational innovation is more likely to bring long-run benefits that the latter one. Conversely, in pre-modern societies, many barriers were erected to keep innovations secret, either out of protectionism or as an attempt by the ruling government to preserve the political power. ${ }^{25}$ The scientific revolution of the seventeenth century, arguably, accelerated the process of transforming knowledge into a public good, and it may have shortened the waiting time for the onset of formal education. Mokyr (2005), for instance, highlights the proliferation of scientific and trade organizations, and the systematic collection of 'useful' knowledge into encyclopedias at the turn of the 18th century as two clear signs that knowledge was increasingly nonproprietary and that discoveries were becoming more like public goods. Finally, the requirement that the patent blueprint be disclosed to the public may have also facilitated the dissemination of knowledge through formal education.

Acknowledgement. I would like to thank seminar participants at the University of North Carolina, Chapel Hill, for suggestions, Federico Bonetto for the many explanations on the properties of dynamic systems, two anonymous referees for numerous critical comments, and Huw Lloyd-Ellis for his valuable editorial guidance. All remaining errors are mine.

\footnotetext{
${ }^{25}$ In the 14th century, Venetian glassmakers were not allowed to leave the Republic. Those who did could face the death penalty.
} 


\section{Appendix A}

Eqs. (15), (17), (19), (21), and (24), evaluated on the balance growth path, reduce to

$$
\begin{gathered}
0=b u_{E}(\psi)^{-\phi}-\theta u_{I}(\psi)^{1-\beta} \\
0=\left(\frac{1}{\sigma}-a_{5}\right) r+\chi-\frac{\rho}{\sigma} \\
0=a_{1}\left[r-a_{3} \theta(\psi)^{1-\beta} u_{P}\right]+a_{2} \theta u_{I}(\psi)^{1-\beta} \\
0=a_{4}\left[r-a_{3} \theta(\psi)^{1-\beta} u_{P}\right]+\left(a_{2}-1\right) \theta u_{I}(\psi)^{1-\beta}+a_{5} r-\chi
\end{gathered}
$$

and

$$
0=b(\psi)^{-\phi}\left(1-\phi u_{E}-\beta u_{I}\right)-a_{3} \theta(\psi)^{1-\beta} u_{P}
$$

where $a_{1} \equiv-\frac{1-\alpha_{1}-\alpha_{2}}{\alpha_{1}}, a_{2} \equiv(1 / \gamma-1) \frac{\alpha_{2}}{\alpha_{1}}, a_{3} \equiv \frac{1-\gamma}{1-\alpha_{1}-\alpha_{2}} \alpha_{2}, a_{4} \equiv-\left(\frac{1-\alpha_{2}}{\alpha_{1}}\right), a_{5} \equiv \frac{1-\gamma \alpha_{2}}{\alpha_{1}}$, and where I have already used Eq. (20) to replace $g_{w}$ in Eq. (19) and (21). In addition, (1) must hold. Thus, we have a system of six equations in six unknowns: $u_{P}, u_{E}, u_{I}, r, \chi$, and $\psi$.

The variable $\chi$ from Eq. (A4) is eliminated through (A2); the resulting equation is combined with (A3) to eliminate $r$. Then, Eq. (A4), after rearrangements, becomes

$$
u_{P}=a_{6} u_{I}+\frac{a_{7}}{(\psi)^{1-\beta}}
$$

where $a_{6}=\left(\sigma / a_{3}\right)\left[\left(a_{4}+1 / \sigma\right) a_{2} / a_{1}\right.$ and $a_{7}=\rho /\left(a_{3} \theta\right)$.

Plugging (A1) into (1), it becomes.

$$
u_{P}=1-\left[\frac{\theta}{b}(\psi)^{1-\beta+\phi}+1\right] u_{I}
$$

Replacing $u_{E}$ and $u_{p}$ in Eq. (A5) by means of Eqs. (A1) and (A5), it reduces to (after rearrangements):

$$
u_{I}=\frac{b(\psi)^{-\phi}-a_{3} \theta a_{7}}{\beta b(\psi)^{-\phi}+\phi \theta(\psi)^{1-\beta}+a_{3} \theta a_{6}} .
$$

Equating the right-hand-side of Eqs. (A6) and (A7) yields

$$
u_{I}=\left[1-\frac{a_{7}}{(\psi)^{1-\beta}}\right] /\left[a_{6}+\frac{\theta}{b}(\psi)^{1-\beta+\phi}+1\right] .
$$

A solution for $\psi$ is found by equating the right-hand-side of the last two equations. Notice that for the non negative constraint on $u_{I}$ to be satisfied, $\psi$ is to be found between $a_{7}^{1 /(1-\beta)}$ and $b /\left(a_{3} \theta a_{7}\right)^{1 / \phi}$. For such a solution to exist, it must be that $\left(1-\alpha_{1}\right) / \alpha_{2}<1+(b / \theta)^{(1-\beta) / \phi} \theta / \rho$. 


\section{References}

Acemoglu, D. and V. Guerrieri (2008), "Capital Deepening and Nonbalanced Economic Growth," Journal of Political Economy, v. 116, issue 3, pp. 467-498.

Acemoglu, D. and S. Johnson (2006), "Disease and Development: The Effect of Life Expectancy on Economic Growth," June, NBER working paper 12269.

Aghion, P. and P. Howitt (1992), "A Model of Growth Through Creative Destruction," Econometrica, 60, pp. 323-702.

Aiyar, S., C. Dalgaard and O. Moav (2008), "Technological Progress and Regress in Preindustrial Times," Journal of Economic Growth, v. 13, iss. 2, pp. 125-44.

Arnold, L. G. (1998), "Growth, Welfare, and Trade in an Integrated Model of Human-capital Accumulation and Research," Journal of Macroeconomics, v. 20, issue 1, pp. 81-105.

Arnold, L. G. (2006), "The Dynamics of the Jones R \& D Growth Model," Review of Economic Dynamics, v. 9 issue 1, pp. 143-152.

Aguiar, M. and E. Hurst (2007), "Measuring Trends in Leisure: The Allocation of Time over Five Decades," Quarterly Journal of Economics, v. 122, issue 3, pp. 969-1006.

Baier, S. L., P. G. Dwyer, Jr., and R. Tamura (2006), "How Important Are Capital and Total Factor Productivity for Economic Growth?" Economic Inquiry, v. 44 issue 1, pp. 23-49.

Barro, R. J. (2006), "Rare Disasters and Asset Markets in the Twentieth Century," Quarterly Journal of Economics, v. 121 issue 3, pp: 823-866.

Becker, G. S., K. M. Murphy and R. Tamura (1990), "Human Capital, Fertility, and Economic Growth," Journal of Political Economy, v. 98, issue 5, pp. S12-S37.

Benhabib, J., and R. Perli (1994), "Uniqueness and Indeterminacy: On the Dynamics of Endogenous Growth," Journal of Economic Theory, v. 63, issue 1, pp. 113-42.

Benhabib J. and M. M. Spiegel (2005), "Human Capital and Technology Diffusion," in Philippe Aghion and Steven Durlauf, eds., Handbook of Economic Growth, Vol 1A. Amsterdam: North-Holland, pp. 935-966.

Ben-Porath, Y. (1967), "The Production of Human Capital and the Life Cycle of Earnings," Journal of Political Economy, 1967, vol 75, pp: 352-365.

Bils, M. and P.J. Klenow (2000), "Does Schooling Cause Growth?" American Economic Review, v. 90, issue 5, pp. 1160-1183.

Borst, H.G. (2001), "The History of Coronary Artery Surgery: A Brief Review," The Thoracic and Cardiovascular Surgeon, 49 (4), pp. 195-98. 
Boucekkine, R., D. de la Croix and O. Licandro (2002), "Vintage Human Capital, Demographic Trends, and Endogenous Growth," Journal of Economic Theory, v. 104, iss. 2, pp. 340-75

Boucekkine, R., D. de la Croix, O. Licandro (2003), "Early Mortality Declines at the Dawn of Modern Growth" Scandinavian Journal of Economics, v. 105, issue 3, pp. 401-18

Bradley, P. (2006) "The History of Simulation in Medical Education and Possible Future Directions," Medical Education, 40, pp. 254-262.

Brunner, M. and H. Strulik (2002), "Solution of Perfect Foresight Saddlepoint Problems: A Simple Method and Applications," Journal of Economic Dynamics and Control, v. 26, issue 5, pp. $737-53$.

Cervellati, M. and U. Sunde (2005), "Human Capital Formation, Life Expectancy and the Process of Development," American Economic Review, v. 95 (5), pp. 1653-1672.

Clark, G. (2005), "The Condition of the Working-Class in England, 1209-2004," Journal of Political Economy, v. 113, issue 6, pp. 1307-40.

Department of Health and Human Services, National Center for Health Statistics (DHHS) (2006), National Vital Statistics Reports, vol 54., no. 19, June 28, 2006.

Diamond, J. (1997), Guns, Germs, and Steel: The Fates of Human Societies, Norton \& Company, New York, NY.

Dosi, G. and R. R. Nelson (2010), "Technical Change and Industrial Dynamics as Evolutionary Processes," in B. H. Hall, and N. Rosemberg eds., Handbooks in Economics of Innovations, v. 1., ch. 3, Amsterdam: North-Holland.

Eaton, J. and S. Kortum (1999), "International Technology Diffusion: Theory and Measurement," International Economic Review, v. 40 issue 3, pp: 537-570.

Easterlin, R. A. (1981), "Why Isn't the Whole World Developed?" Journal of Economic History, v. 41 issue 1, pp. 1-19.

Eicher, T. S. and S. J. Turnovsky (2001), "Transitional Dynamics in a Two-sector Non-scale Growth Model," Journal of Economic Dynamics \&3 Control, v. 25 issue 1/2, pp. 85-113.

Funke, M. and H. Strulik (2000), "On Endogenous Growth with Physical Capital, Human Capital and Product Variety," European Economic Review, Mar 2000, v. 44 issue 3, pp. 491-515.

Galor, O. (2005), "From Stagnation to Growth: Unified Growth Theory," in Philippe Aghion and Steven Durlauf, eds., Handbook of Economic Growth, Vol 1A. Amsterdam: NorthHolland, pp: 171-292. 
Galor, O. and O. Moav, (2002), "Natural Selection and the Origin of Economic Growth," Quarterly Journal of Economics, v. 117 issue 4, pp: 1133-1191

Galor, O. and D. N. Weil (2000), "Population, Technology, and Growth: From Malthusian Stagnation to the Demographic Transition and Beyond," American Economic Review, v. 90 issue 4, pp. 806-828.

Gordon, R. J. (2005), "Interpreting the 'One Big Wave' in U.S. Long-Term Productivity Growth," National Bureau of Economic Research, (Cambridge, MA) Working Paper No. 7752 .

Graham, S. J. H. and D. C. Mowrey (2004), "Submarines in Software? Continuations in US Software Patenting in the 1980s and 1990s," Economics of Innovation and New Technology, Special Issue v. 13, issue 5, pp. 443-56.

Grossman, G. M. and E. Helpman (1991), Innovation and Growth in the Global Economy, Cambridge, Mass.: MIT Press.

Hall, B.H. and R. H. Ziedonis (2001), "The Determinants of Patenting in the U.S. Semiconductor Industry, 1980-1994," Rand Journal of Economics, 32, 101-128.

Hazan, M. and H. Zoabi (2006), "Does Longevity Cause Growth? A Theoretical Critique," Journal of Economic Growth, vol 11, pp: 363-376.

Jones, B. F (2009), "The Burden of Knowledge and the 'Death of the Renaissance Man': Is Innovation Getting Harder?" Review of Economic Studies, v. 76, issue 1, pp. 283-317.

Jones, C. I. (2005), "Growth and Ideas," in Philippe Aghion and Steven Durlauf, eds., Handbook of Economic Growth, Vol 1B. Amsterdam: North-Holland, pp: 1063-1111.

Jovanovic, B. and P. L. Rousseau (2005). "General Purpose Technologies," in Philippe Aghion and Steven Durlauf, eds., Handbook of Economic Growth, Vol 1B. Amsterdam: NorthHolland, pp: 1181-1224.

Kamien, M.I. and N.L. Schwartz (1991). Dynamic Optimization: The Calculus of Variations and Optimal Control in Economics and Management, 2nd edition, New York, North Holland. King, R. G. and S. T. Rebelo (1993), "Transitional Dynamics and Economic Growth in the Neoclassical Model," American Economic Review, v. 83, issue 4, pp. 908-922.

Kirby, P. (2003), Child Labor in Britain, 1750-1870. Palgrave-MacMillan, Basingstoke.

Klenow, P. J. and A. Rodríguez-Clare (2005), "Externalities and Growth," in Philippe Aghion and Steven Durlauf, eds., Handbook of Economic Growth, Vol 1A. Amsterdam: North-Holland, 2005, pp: 817-863.

Kongsamut, P., S. Rebelo and D. Xie (2001), "Beyond Balanced Growth," Review of Economic Studies, v. 68, issue 4, pp. 869-82. 
Kosempel, S. (2004), "A Theory of Development and Long Run Growth," Journal of Development Economics, v. 75, issue 1, pp. 201-220.

Lloyd-Ellis, H. and J. Roberts (2002), "Twin Engines of Growth: Skills and Technology as Equal Partners in Balanced Growth," Journal of Economic Growth, v. 7, issue 2, pp. 87-115.

Lucas Jr., R. E. (1998), "On the Mechanics of Economic Development," Journal of Monetary Economics, v. 22, issue 1, pp. 3-42.

Maddison, A. (2003), The World Economy: Historical Statistics, OECD Development Centre, Paris.

Mokyr, J. (2005). "Long-Term Economic Growth and the History of Technology," in Handbook of Economic Growth, eds. Philippe Aghion and Steven N. Durlauf. Amsterdam : Elsevier.

Nelson, R. R. and E. S. Phelps (1966), "Investment in Humans, Technological Diffusion, and Economic Growth," American Economic Review 61, pp: 69-75.

Ortigueira, S. and M. S. Santos (1997), "On the Speed of Convergence in Endogenous Growth Models," American Economic Review, v. 87, issue 3, pp. 383-399.

Palis J., and W. DeMelo (1982), Geometric Theory of Dynamical System, New York, Springer.

Ramey, V. A. and N. Francis (2009), "A Century of Work and Leisure," American Economic Journal: Macroeconomics, v. 1, issue 2, pp. 189-224.

Romer, P. M. (1990), "Endogenous Technological Change," Journal of Political Economy, Part 1, v. 98, issue 5, pp. S71-S102.

Rebelo, S. (1991). "Long-Run Policy Analysis and Long-Run Growth," Journal of Political Economy, v. 99, issue 3, pp. 500-52.

Schofer, E. and J. W. Meyer (2005), "The Worldwide Expansion of Higher Education in the Twentieth Century," American Sociological Review, Vol 70(6), pp. 898-920.

Siegel, J. (1998), Stocks for the Long Run: The Definitive Guide to Financial Market Returns and Long Term Investment Strategies, New York: Irwin Professional Publishing.

Soares, S. S. (2005), "Mortality Reductions, Educational Attainment, and Fertility Choice," American Economc Review, v. 95 (3), pp: 580-601.

Stephens, W. B. (1998), Education in Britain 1750-1914, Basingstock.

Stokey, N. (1991), "Human Capital, Product Quality and Growth," Quarterly Journal of Economics, 106 (2), pp. 587-616.

Tamura, R. F. (1991), "Income Convergence in and Endogenous Growth Model," Journal of Political Economy, 99, pp: 522-540. 
Terman, F. E. (1998), "A Brief History of Elelctrical Engineering Education," Proceedings of the IEEE, v. 86, N0 8, pp. 1-9, reprinted from the Proceedings of the IEEE, v. 64 no. 9, pp. 1399-1406, Sept. 1976.

Udry, C. and S. Anagol (2006), "The Return to Capital in Ghana," American Economic Review, v. 96, issue 2, pp. 388.

Uzawa, H. (1965), "Optimum Technical Change in an Aggregative Model of Economic Growth," International Economic Review, v. 6, pp. 18-31. 
Figure 1: Two-dimensional path in an education-innovation growth model

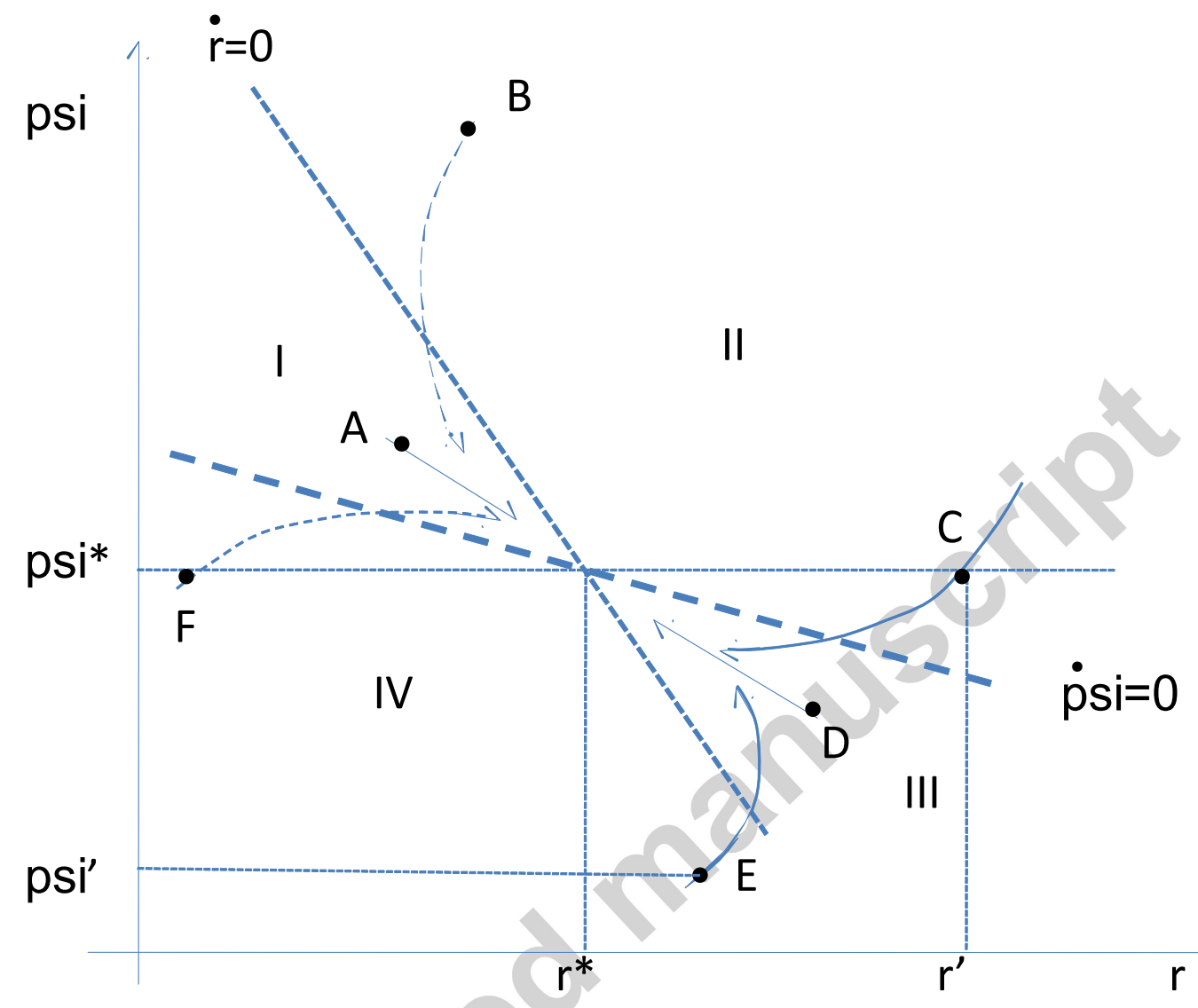

Note. - Any trajectory starting from any of the four regions converge to the node $\left(r^{*}, \psi^{*}\right)$. Point A and $\mathrm{D}$ lie along the direction of the eigenvector $v_{21}$ (details are contained in Appendix $\mathrm{C}$, available on my personal webpage).

Table 2: Baseline Parameters

\begin{tabular}{llllllllll}
\hline \hline$z$ & $\alpha_{1}$ & $\alpha_{2}$ & $\gamma$ & $\theta$ & $b$ & $\phi$ & $\beta$ & $\sigma$ & $\rho$ \\
\hline 1 & 0.162 & 0.46 & 0.6 & 0.1 & 0.055 & 0.4 & 0.5 & 2 & 0.02 \\
\hline
\end{tabular}

Table 3: Values of Variables on the Balanced Growth Path

\begin{tabular}{llllllll}
\hline$r$ & $y / k_{1}$ & $g_{y}$ & $\psi$ & $\chi$ & $u_{E}$ & $u_{I}$ & $u_{P}$ \\
\hline 0.05 & 0.3088 & 0.015 & 1.384 & 0.2086 & 0.1739 & 0.0714 & 0.7547 \\
\hline
\end{tabular}


Figure 2: Productivity shock and destruction of physical capital
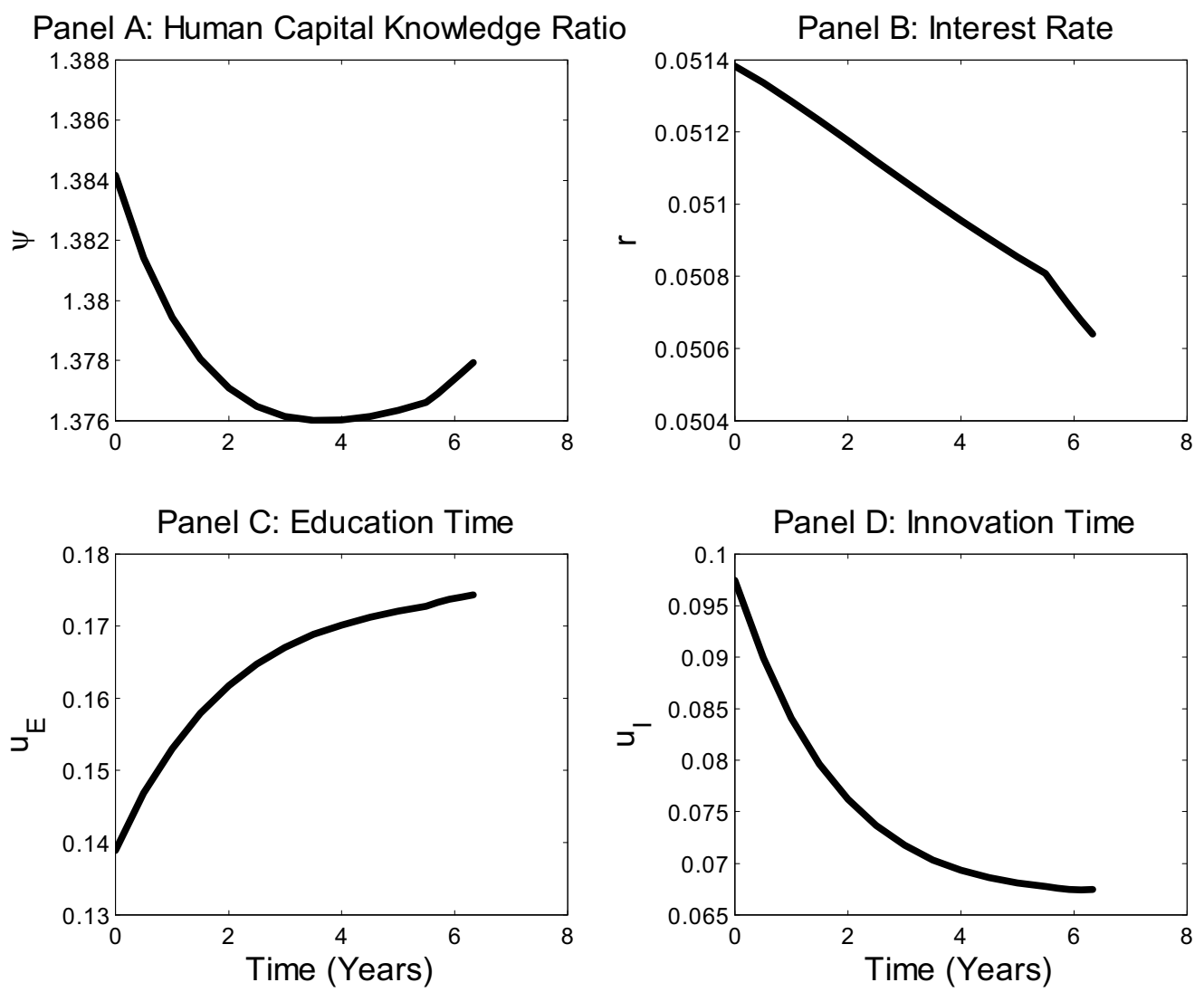

Note. - Adjustment process of the economy when it is hit by a positive productivity shock of $1 \%$. Before the shock the economy is on the steady state, namely, $\psi=1.384, r=0.05, u_{E}=0.1739$, and $u_{I}=0.0714$. See Tables (2) and (3) for underlying parameters and the values of other variables on the balanced growth path. The immediate effect of the disturbance is recorded in Table (5), row (1). In particular, the interest rate goes from 5 to $5.14 \%$, the schooling time declines from 0.1739 to 0.14 , and the innovation time increases from 0.0714 to 0.0976 . The human capital-knowledge ratio is not affected initially; however, during the adjustment process, it first declines, as a consequence of the diminished educational activity and of the augmented innovation activity, and then it picks up again, as schooling time rises and innovation time declines. The dynamics of the variables plotted in the four graphs would be the same if the same economy were hit by a negative shock on physical capital of $2.68 \%$, but other variables would respond differently, as shown in row (2) of Table (5). 
Figure 3: Inflow of knowledge
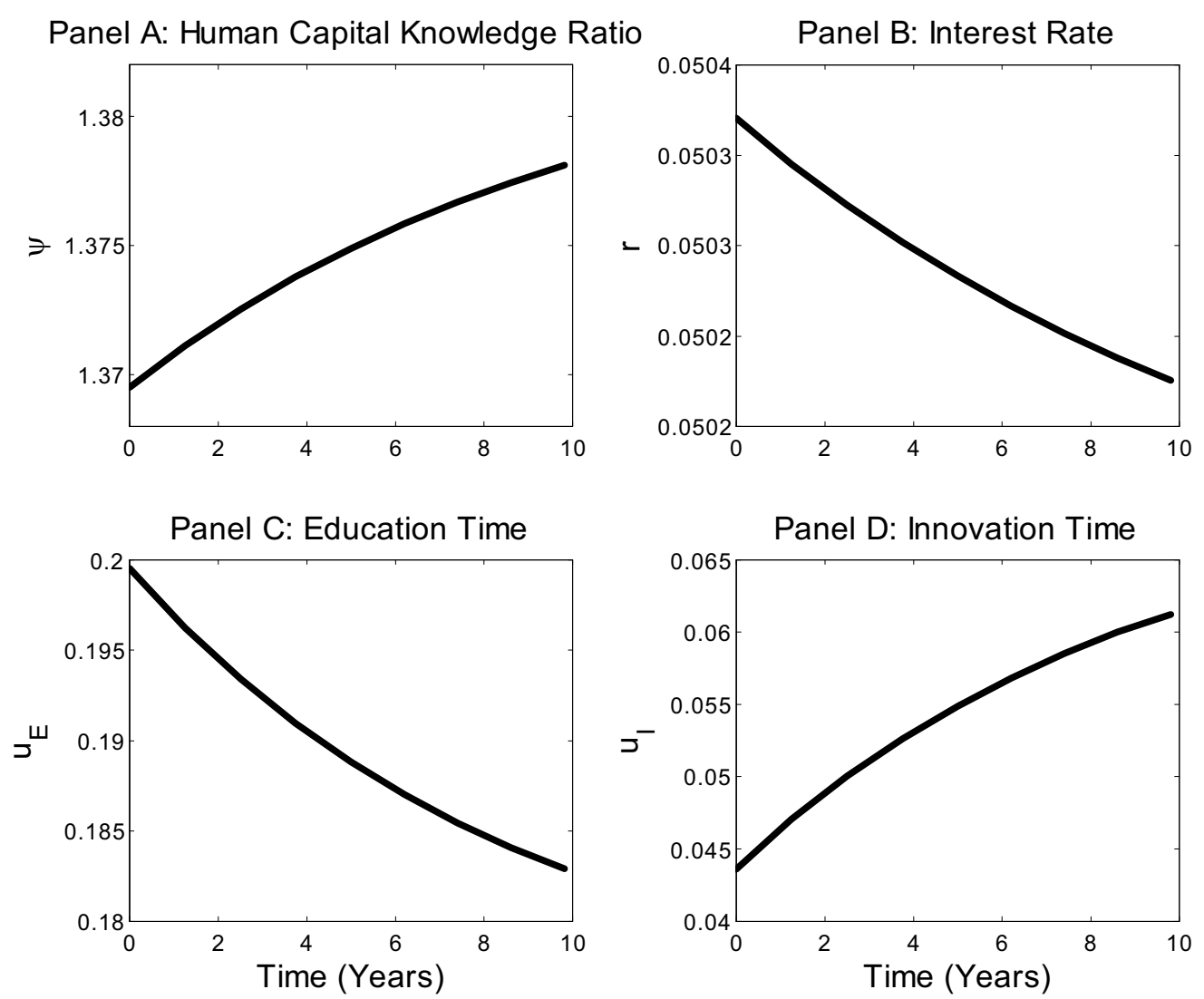

Note. - The figure shows the adjustment process of positive shock to $n$ of $1 \%$. The parameters and starting position are the same as in the previous figure. The interest rate increases as a consequence of the greater productivity of physical capital. Innovation goes down, partly because of the devaluation effect of the sudden increase in product variety, partly because schooling becomes more valuable.

\section{Table 4: Comparative Dynamics}

\begin{tabular}{llllllllll}
\hline \hline & $\sigma$ & $\rho$ & $\theta$ & $b$ & $\phi$ & $\beta$ & $\alpha_{1}$ & $\alpha_{2}$ & $\gamma$ \\
\hline$u_{E}$ & - & - & + & + & - & - & $\cap$ & $\cap$ & $\cap$ \\
$u_{I}$ & - & - & + & + & - & - & $\cap$ & + & - \\
$\psi$ & - & - & - & + & - & + & + & - & + \\
$\chi$ & + & + & + & + & - & - & - & + & - \\
$r$ & + & + & + & + & - & - & - & + & - \\
$g_{y}$ & - & - & + & + & - & - & - & + & - \\
\hline
\end{tabular}

Note. The $+(-)$ sign indicates that the variable evaluated at the steady state is increasing (decreasing) in the parameter. The sign $\cap$ denotes an inverted-U relationship. The model is parametrized with the set of values reported in table (2). 
Figure 4: Calibration of the Transitional Dynamics
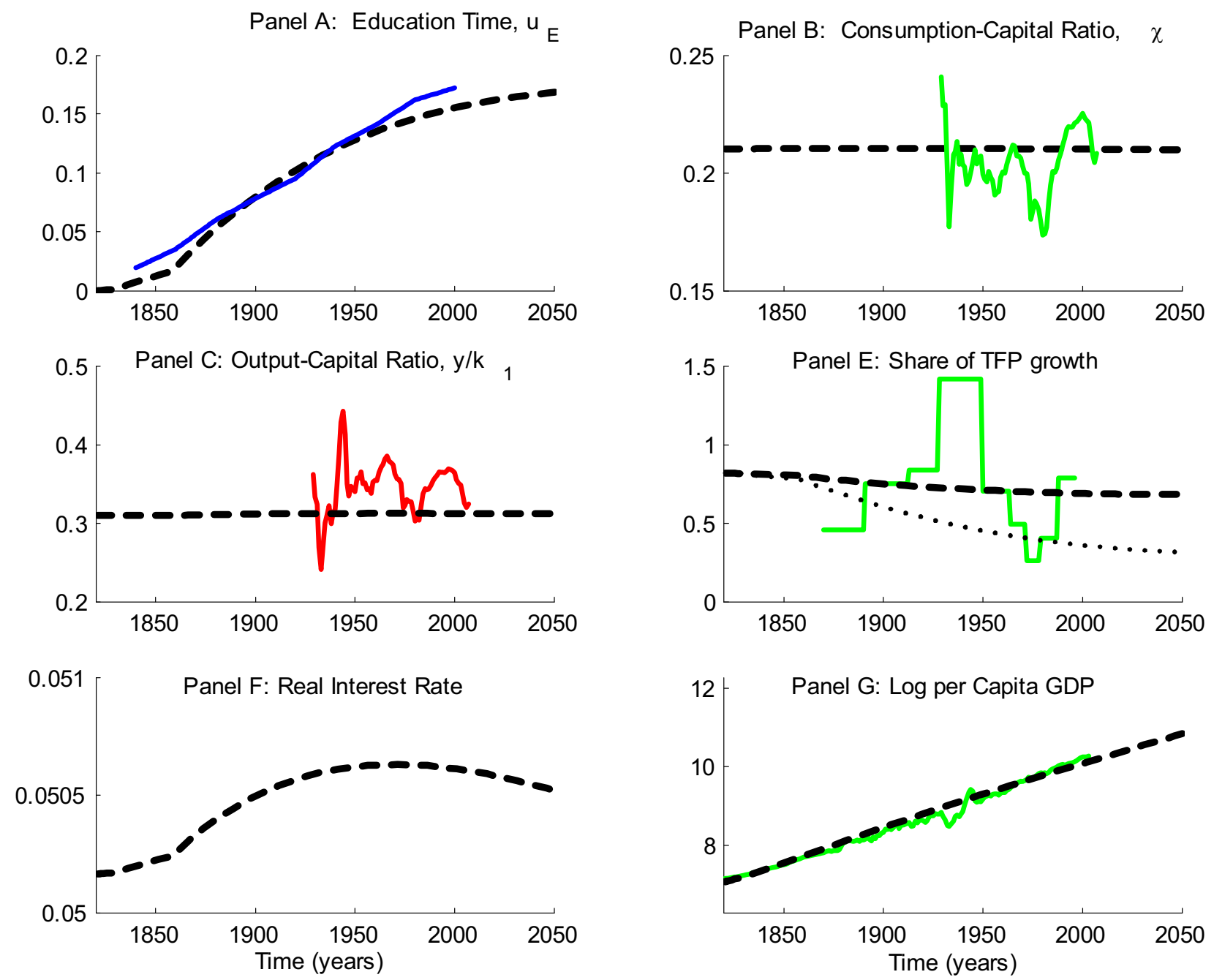

Note. - The dashed line plotted in Panels A through F represent the trajectories implied by the model under the baseline parameters in Table (2). The continuous lines show the relevant U.S. time series. Details on how $u_{E}$ was estimated are in Table (6). For a description the actual TFP ratio (continuous line) see note of Table (7). Panel $\mathrm{C}$ plots two dashed lines. The top one includes the contribution of both technological progress and education; the bottom one includes innovation only. A simple linear regression against time of the consumption-capital ratio data series yields a 0.0001 slope and an intercept of 0.20 . A similar regression performed on the simulated ratio delivers 0 and 0.21. A comparison for $y / k_{1}$ generated 0.34 (data) vs. 0.31 (model) with nearly zero slopes in both the model and the data. As for the TFP, there is no trend in the data, whereas simulations produce a negative trend of -0.0006 , when TFP includes human capital, and -0.0021 when it does not. For a discussion of the time series on the interest rate (Panel F) see section 8.1. 
Table 5: Immediate Effects of Four Shocks

\begin{tabular}{|c|c|c|c|c|c|c|c|c|c|}
\hline & \multirow[t]{2}{*}{ source \impact } & \multicolumn{4}{|c|}{ absolute variation } & \multicolumn{4}{|c|}{ percentage variation } \\
\hline & & $u_{p}$ & $u_{E}$ & $u_{I}$ & $r$ & $w$ & $c$ & $\chi$ & $\mu / \lambda$ \\
\hline (1) & $z$ (positive) & 0.0089 & -0.035 & 0.0261 & 0.0014 & 1.52 & 1.75 & 1.75 & 1.52 \\
\hline$(2)$ & $k_{1}$ (negative) & 0.0040 & -0.017 & 0.0126 & 0.0005 & -0.46 & -0.30 & 0.70 & -0.46 \\
\hline$(3)$ & $n$ (positive) & 0.0021 & 0.026 & -0.0278 & 0.0003 & 0.50 & 0.33 & 0.33 & 0.09 \\
\hline (4) & $h$ (negative) & -0.0014 & 0.040 & -0.0387 & -0.0003 & 0.37 & -0.51 & -0.51 & -0.05 \\
\hline
\end{tabular}

Note. - The first row reports the immediate effects of a positive shock of one percent to $z$. For the first four variables (starting from the left) the change is in absolute terms (in the case of the interest rate it is in basis points), whereas for the remaining variables it is in percentages. The remaining three rows report the outcome of a one per cent negative shock on $k_{1}$ and $h$ and a one per cent positive shock on $n$. In all cases the starting position is the Balanced Growth Path described in Tables (2) and (3).

Table 6: Fraction of Time Spent to Acquire Human Capital

\begin{tabular}{lcccccc}
\hline \hline Time & 1840 & 1900 & 1940 & 1960 & 1980 & 2000 \\
\hline Years of school & 1.14 & 4.83 & 8.28 & 9.83 & 11.7 & 13 \\
Life span & 58.92 & 61.39 & 67.39 & 70.01 & 72.21 & 75.55 \\
$u_{E}$ (estimate) & 0.012 & 0.079 & 0.123 & 0.1404 & 0.1620 & 0.1721 \\
\hline
\end{tabular}

Note. - The first row reports the average years of schooling of the labor force estimated in Baier et al. (2007, Table 1). The life span is calculated on the basis of estimates of life expectancy of 10 and 20 year-old white males provided by the DHHS (2006). The life expectancy in 1840 and 1900 is interpolated from observations of the year 1850 and 1890. The fourth row reports the ratio between the first and the second row.

Table 7: Ratio between the rate of growth of TFP and that of per capita GDP

\begin{tabular}{cccccccccc}
\hline \hline Time & $1870-91$ & $1891-1913$ & $1913-28$ & $1928-50$ & $1950-64$ & $1964-72$ & $1972-79$ & $1979-88$ & $1988-96$ \\
Ratio & 0.46 & 0.75 & 0.84 & 1.42 & 0.70 & 0.49 & 0.26 & 0.40 & 0.79 \\
\hline
\end{tabular}

Note. - The growth accounting is based on Gordon (2000, Table 1). The production factors are not adjusted for quality. 
Table 8: Calibration on the Balanced Growth Path

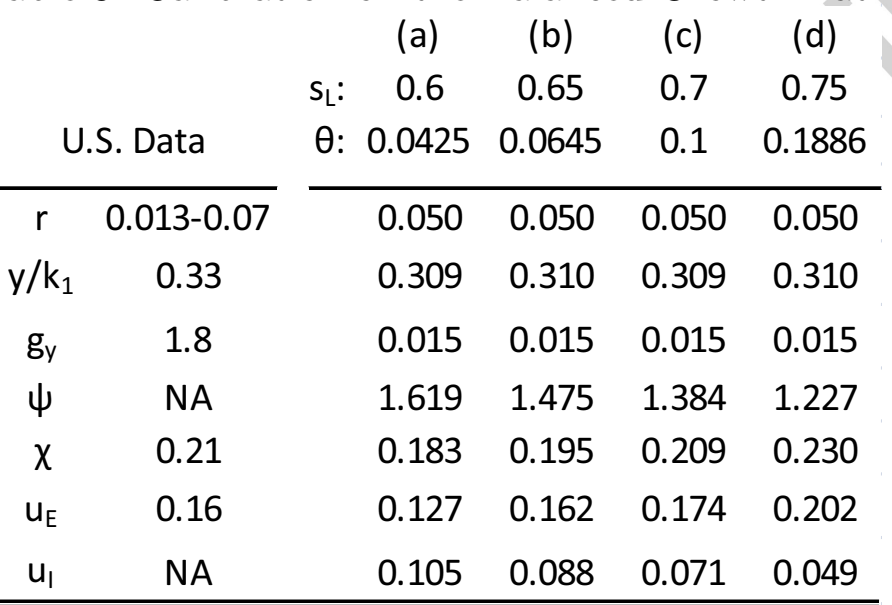

Note. - The table compares the values of the seven key model variables evaluated at the BGP against the corresponding U.S. data - when available. In column (c), the model is evaluated under the set of parameters displayed in Table (2), row (1). Column (a), (b), and (d) consider three alternative values for the output elasticity to skilled labor. In each case $\theta$ is adjusted to maintain the interest rate at $5 \%$ and $g_{y}$ at $1.5 \%$. The data values are approximate averages over the length of the available time series, except for $\mathrm{u}_{E}$, that refers to the year 2,000 . 